\title{
Extracellular vesicle-mediated amyloid transfer to neural progenitor cells: implications for RAGE and HIV infection
}

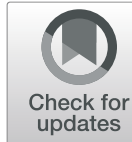

Ibolya E. András ${ }^{\text {* }}$, Marta Garcia-Contreras², Christopher Yanick', Paola Perez , Brice Sewell ${ }^{1}$, Leonardo Durand ${ }^{1}$ and Michal Toborek ${ }^{1 *}$ (D)

\begin{abstract}
Amyloid beta (Aß) deposition was demonstrated to be elevated in the brains of HIV-infected patients and associated with neurocognitive decline; however, the mechanisms of these processes are poorly understood. The goal of the current study was to address the hypothesis that $A \beta$ can be transferred via extracellular vesicles (ECVs) from brain endothelial cells to neural progenitor cells (NPCs) and that this process can contribute to abnormal NPC differentiation. Mechanistically, we focused on the role of the receptor for advanced glycation end products (RAGE) and activation of the inflammasome in these events. ECVs loaded with A (Aß-ECVs) were readily taken up by NPCs and A $\beta$ partly colocalized with the inflammasome markers ASC and NLRP3 in the nuclei of the recipient NPCs. This colocalization was affected by HIV and RAGE inhibition by a high-affinity specific inhibitor FPS-ZM1. Blocking RAGE resulted also in an increase in ECV number produced by brain endothelial cells, decreased A $\beta$ content in ECVs, and

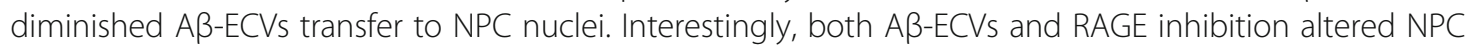
differentiation. Overall, these data indicate that RAGE inhibition affects brain endothelial ECV release and AB-ECVs transfer to NPCs. These events may modulate ECV-mediated amyloid pathology in the HIV-infected brain and contribute to the development of HIV-associated neurocognitive disorders.
\end{abstract}

Keywords: Extracellular vesicles, Blood-brain barrier, Amyloid beta, Neural progenitor cells, RAGE

\section{Introduction}

HIV-infected brains were shown to have increased amyloid beta $(A \beta)$ deposition [1-6]. This phenomenon has been linked to the development of cognitive dysfunction based on the observation that early beta-amyloidosis in HIV-infected patients was associated with HIV-associated neurocognitive disorders (HAND) [3, 7]. A $\beta$ deposition occurs mostly in the perivascular space [3, 7-9], which points to the brain microvessels having a role in amyloid pathology. In support of this notion, the blood-brain barrier (BBB), a critical player in the brain infection by HIV and the development of HIV-associated cerebrovascular comorbidities $[10,11]$, was postulated to regulate $A \beta$ homeostasis as an interface contributing to $A \beta$

\footnotetext{
* Correspondence: iandras@med.miami.edu; mtoborek@med.miami.edu 'Department of Biochemistry and Molecular Biology, University of Miami School of Medicine, 1011 NW 15th Street, Gautier Building, Room 528, Miami, FL 33136-1019, USA

Full list of author information is available at the end of the article
}

accumulation in the brain [12]. Indeed, it was demonstrated that the receptor for advanced glycation end products (RAGE) can mediate $\mathrm{A} \beta$ transport across the $\mathrm{BBB}$ and accumulation in the brain [13]. Similarly, RAGE was shown to be involved in HIV-induced accumulation of $A \beta$ in brain endothelial cells, a structural component of the BBB [14].

Extracellular vesicles (ECVs), such as exosomes, were demonstrated before to be important in HIV and $A \beta$ pathology [15-21]. We observed that HIV increased the shedding of ECVs carrying $A \beta$ from brain endothelial cells. Moreover, brain endothelial cellderived ECVs transferred $A \beta$ to cells of the neurovascular unit, namely to astrocytes and pericytes [22], prompting us to hypothesize that a similar process may also increase $A \beta$ exposure of other cells found in close proximity of the brain microvessels, including the neural progenitor cells (NPCs). In fact, $\sim 47 \%$ of dividing progenitor and $46 \%$ of transit amplifying cells

(c) The Author(s). 2020 Open Access This article is distributed under the terms of the Creative Commons Attribution 4.0 International License (http://creativecommons.org/licenses/by/4.0/), which permits unrestricted use, distribution, and 
(i.e., cells that give rise to neuroblasts) are located within $5 \mu \mathrm{m}$ of the endothelium [23, 24].

In this work we aimed to evaluate possible mechanisms involved in shedding of ECVs by brain endothelial cells and $A \beta-E C V s$ transfer to NPCs. Because $A \beta-E C V s$ may affect neurogenesis [25], we also focused on the impact of this process on differentiation of NPCs into neurons. The importance of this line of experimentation is related to the notion that aberrant NPC differentiation and neurogenesis may contribute, at least in part, to the cognitive deficits observed in HIV-infected patients [26].

Based on the observations that a) HIV can increase RAGE expression in brain endothelial cells [14], b) HIVinduces $A \beta$ accumulation in brain endothelial cells via a RAGE-dependent mechanism [14], and c) RAGE may be involved in microvesicle secretion [27], we hypothesize in the current study that RAGE may be a key player in the HIV-induced brain endothelial ECV release and A $\beta$ ECVs transfer to NPCs. In addition, because both HIV infection [28] and $A \beta$ pathology $[29,30]$ were linked to the inflammasome pathway, and RAGE was shown to signal through the NLR family pyrin domain containing 3 (NLRP3) inflammasome [31], we further aimed to examine the impact of A $\beta-E C V$ transfer on the NLRP3 inflammasome in NPCs.

\section{Materials and methods \\ Cell cultures}

\section{Human brain microvascular endothelial cells (HBMEC)}

HBMEC used in the present study represent a stable, well characterized, and differentiated human brain endothelial cell line [32]. Briefly, normal human brain endothelial cells were transduced by lentiviral vectors incorporating human telomerase or SV40T antigen. Among several stable immortalized clones obtained by sequential limiting dilution cloning of the transduced cells, the hCMEC/D3 cell line (referred here as HBMEC) was selected as expressing normal endothelial markers and demonstrating blood-brain barrier characteristics. HBMEC for the present study were supplied by Dr. Couraud (Institut Cochin, Paris, France). HBMEC were cultured on collagen type I (BD Biosciences Pharmingen, San Jose, CA) coated dishes in EBM-2 medium (Clonetics, East Rutherford, NJ) supplemented with VEGF, IGF-1, EGF, basic FGF, hydrocortisone, ascorbate, gentamycin and $0.5 \%$ exosome depleted fetal bovine serum (Exo-FBS; System Biosciences, Mountain View, CA).

\section{Human neural progenitor cells (NPCs)}

An immortalized NPC line ReNcell VM, derived from 10-week human ventral mesencephalon, was obtained from Millipore and cultured according to the manufacturer's protocols. The cells were validated for high expression of Sox2 and nestin as well as for their self-renewal and differentiation capacity. Cells were grown on laminin coated tissue culture dishes in a maintenance medium (Millipore), containing $20 \mathrm{ng} / \mathrm{ml} \mathrm{FGF-2}$ and $20 \mathrm{ng} / \mathrm{ml}$ of rhEGF. Cells were used for experiments at $<80 \%$ confluence, 3 days after plating.

\section{HIV infection and treatment factors}

HIV stock was generated using human embryonic kidney (HEK) $293 \mathrm{~T}$ cells (ATCC) transfected with pYKJRCSF plasmid containing full-length proviral DNA. Throughout the study, HBMEC were exposed to HIV particles at the p24 level of $30 \mathrm{ng} / \mathrm{ml}$ as previously reported [33]. Treatment was terminated by removing cell culture media containing HIV, followed by washing the cells in PBS.

$A \beta(1-40)$ and $A \beta(1-40)$ HiLyte were purchased from Anaspec (San Jose, $C A$ ) and $A \beta(1-40)$ was dissolved in PBS. Freshly solubilized A $\beta$ solutions without preaggregation were used for experiments as such a form of $\mathrm{A} \beta$ was demonstrated to induce proinflammatory reactions in isolated rat brain microvessels [34]. A $\beta$ (1-40) HiLyte was dissolved first in a basic buffer $(0.1 \mathrm{M}$ $\mathrm{NH}_{4} \mathrm{OH}$ ) and then diluted further in PBS as suggested by the manufacturer. Cells were treated with $A \beta(1-40)$ or $\mathrm{A} \beta(1-40)$ HiLyte at the concentration of $100 \mathrm{nM}$ in complete medium.

FPS-ZM1 (FPS, Cayman Chemicals, Ann Arbor, MI, USA) is a high-affinity RAGE-specific inhibitor [35]. 1 $\mathrm{mM}$ stock solution was prepared in DMSO. Cells were pretreated with $500 \mathrm{nM}$ FPS for $2 \mathrm{~h}$ followed by coexposure with HIV and/or $100 \mathrm{nM} \mathrm{A} \beta$ (1-40).

GW 4869 (Millipore Sigma, Burlington, MA, USA) is a cell-permeable, non-competitive inhibitor of neutral sphingomyelinases. $5 \mathrm{mM}$ stock solution of GW4869 was prepared in DMSO. Because of low solubility, the stock was incubated at $37^{\circ} \mathrm{C}$ for $15 \mathrm{~min}$ and supplemented with $1 / 20$ volume of $5 \%$ methane-sulfonic acid (MSA) before adding GW4869 to cell culture medium [36]. Control cultures were exposed to vehicle, i.e., 0.4\% DMSO supplemented with $1 / 20$ volume of $5 \%$ MSA. Cells were pretreated with the solubilized GW4869 $(20 \mu \mathrm{M})$ for $1 \mathrm{~h}$ followed by coexposure with HIV and/or $100 \mathrm{nM} \mathrm{A} \beta(1-40)$.

\section{Treatment of brain endothelial cells and ECV isolation}

Confluent HBMEC were exposed to HIV and/or A $\beta$ (140)/A $\beta$ (1-40) HiLyte for $48 \mathrm{~h}$. ECVs were isolated from conditioned medium using ExoQuick-TC exosome precipitation solution (System Biosciences) according to the manufacturer's specifications. Briefly, $10 \mathrm{ml}$ culture medium (from $1.7 \times 10^{7}$ cells at confluency cultured in a P100 dish) was centrifuged at $3000 \mathrm{~g}$ for $15 \mathrm{~min}$ to remove cells and debris. Then, the samples were mixed 
thoroughly with $2 \mathrm{ml}$ of Exo-Quick exosome precipitation solution and incubated overnight at $4{ }^{\circ} \mathrm{C}$. The next day, the samples were centrifuged at $1500 \mathrm{~g}$ for $30 \mathrm{~min}$, the supernatants were removed and centrifuged again at $1500 \mathrm{~g}$ for $5 \mathrm{~min}$. The ECV pellets were resuspended in $400 \mu \mathrm{l} \mathrm{PBS}$ and used for further studies. The aliquots of $20 \mu \mathrm{l}$ of ECV suspension for every $100 \mu \mathrm{l}$ of cell culture media was used for NPC treatment.

\section{Nanoparticle tracking analysis (NTA)}

ECVs were analyzed by NanoSight model NS300 (Malvern Instruments Company, Nanosight, Malvern, United Kingdom) as described earlier [22]. Briefly, ECV pellet samples obtained in the process of ECV isolation were resuspended in $100 \mu \mathrm{l} 4 \%$ paraformaldehyde-PBS and further diluted 100 fold in PBS for analysis. Three $90 \mathrm{~s}$ videos were recorded for each sample. The obtained data were analyzed using Nanosight NTA 2.3 Analytical Software (Malvern Instruments Company) with the detection threshold optimized for each sample and screen gain at 10 to track the maximal number of particles with minimal background. Most of isolated ECVs carry fluorescent $A \beta$ (1-40) cargo. In addition, $A \beta$ is associated with ECVs of different size (see Additional file 1: Figure S1).

\section{Protein isolation and western blot}

Proteins from NPCs were extracted with Radio Immuno Precipitation Assay (RIPA) buffer (Pierce, IL, USA) with freshly added protease inhibitors and $1 \%$ Triton-X 100 to inactivate HIV. ECV protein concentration was measured by BCA protein assay kit (Pierce). Equal amount of proteins $(8-16 \mu \mathrm{g} / \mathrm{lane})$ was loaded on sodium dodecyl sulfate polyacrylamide 4-20\% ready gels (BioRad, Hercules, CA) and electrotransferred to a nitrocellulose membrane using a transfer pack system (BioRad). The blots were probed at $4{ }^{\circ} \mathrm{C}$ with rabbit anti-ASC antibody (Catalog \# AL177, Adipogen Life Sciences, San Diego, CA), rabbit anti-NLRP3 antibody (Catalog \# LSB4321, LSBio, Seattle, WA) or mouse anti-caspase-1 antibody (Catalog \# sc-514, Santa Cruz Biotechnology Inc) (1:400) in $5 \%$ milk-TBS-T. After washing 3 times with TBS-T, the samples were incubated with secondary antibodies diluted at 1:20,000 (anti-mouse $800 \mathrm{CW}$ or anti-rabbit 680RD). Anti-GAPDH antibody conjugated with Dylight 680 (1:20,000; Novus Biologicals, Littleton, CO, USA) was employed as an internal control. Signal detection was performed using Image Studio 4.0 software (LICOR). In our cells, the $16.5 \mathrm{kDa}$ ASC band corresponded to a splice variant according to the manufacturer. For NLRP3, additional bands were found above and below the manufacturer-predicted $101,114 \mathrm{kDa}$ bands. For caspase-1 a very weak band of $\sim 40 \mathrm{kDa}$ was found (see Additional file 1: Figure S3).

\section{Caspase- 1 activity assay}

Caspase- 1 activity was measured after a $5 \mathrm{~h}$ and $24 \mathrm{~h}$ exposure to ECVs with the Caspase-Glo 1 Inflammasome assay (Catalog \# G9951, Promega, Madison, WI) following the manufacturer's instructions.

\section{Enzyme linked Immunosorbent assay (ELISA)}

ELISA was used to determine levels of total human $A \beta$ (1-40) (R\&D Systems, Minneapolis, MN, USA) in the isolated brain endothelial ECVs. IL-1 $\beta$, VEGF-A and BDNF levels were also measured by ELISA from the cell culture medium after 3 days of NPC differentiation (R \& D Systems).

\section{Fluorescence microscopy}

NPCs $(28,000$ cells/well) were cultured and treated on laminin coated 8-chambered glass slides (ibidi USA, Madison, WI). Then, the cells were washed with PBS and fixed with absolute ethanol for $30 \mathrm{~min}$ at $4{ }^{\circ} \mathrm{C}$. After washing with PBS, nuclei were stained with DRAQ5 for 5 min followed by PBS wash. Slides were mounted using ProLong Gold antifade reagent (Life Technologies). Green fluorescence (originating from $A \beta$ HiLyte Alexa Fluor488) and red fluorescence (from DRAQ5) were acquired directly using a Nikon Eclipse Ti-U fluorescence microscope.

\section{Confocal microscopy}

ECV-treated NPCs cultured on laminin coated chambered glass slides (Becton Dickinson Biosciences, San Jose, CA) were fixed with ethanol for $30 \mathrm{~min}$ at $4{ }^{\circ} \mathrm{C}$. After washing with PBS and blocking with $3 \%$ bovine serum albumin in PBS for $30 \mathrm{~min}$, samples were incubated overnight at $4{ }^{\circ} \mathrm{C}$ with the primary antibody: rabbit anti-ASC polyclonal antibody (Catalog \# AL177, 1:400), rabbit anti-NLRP3 polyclonal antibody (Catalog \# LSB4321, 1:400), mouse anti-Hu C/D monoclonal antibody (Catalog \# A-21271, 1:300) (from Invitrogen, Carlsbad, CA), rabbit anti-NeuN monoclonal antibody (Catalog \# 24307, 1:200, Cell Signaling Technology, Danvers, MA) or mouse anti-doublecortin (DCX) monoclonal antibody (Catalog \# GTX60612, 1:200, GeneTex, Irvine, CA). Then, the excess of primary antibody was removed, slides were washed with $\mathrm{PBS}$, and incubated with Alexa Fluor488/594-conjugated secondary antibody (1:200, Invitrogen) for $2 \mathrm{~h}$ at room temperature. In some experiments, nuclei were stained with DRAQ5 followed by PBS wash. Slides were mounted using ProLong Gold Antifade reagent with or without 4',6-diamidino-2-phenylindole (DAPI, Invitrogen) to visualize the nuclei. Specimens were covered with coverslips and the immunofluorescent images were evaluated and captured under confocal microscopy. Red fluorescence originating from DRAQ5, blue fluorescence from DAPI, and green 
fluorescence from ECV-A $\beta$ HiLyte-Alexa Fluor488 was acquired directly using confocal microscopy (Olympus, Fluoview 1200, dry lens UPLFLN 40x NA: 0.75 or $60 x$ oil immersion lens, room temperature) and did not require the use of primary or secondary antibody.

For $A \beta$ measurements, fields were chosen at random and acquisition and quantification were performed using the FV10-ASW3.1 software. For the nuclear $A \beta$ measurements, mean fluorescence intensity was measured in the nuclear areas outlined by the DRAQ5 or DAPI staining. For ASC and NLRP3 measurements, the total area fluorescence intensity on the acquired images was normalized to the number of nuclei. For the nuclear ASC, NLRP3 measurements, mean fluorescence intensity was measured in random nuclear areas outlined by the DAPI staining.

\section{NPC differentiation}

NPCs were seeded on laminin coated 8-well chambered glass slides $(28,000$ cells/well $)$ and incubated overnight at $37^{\circ} \mathrm{C}$ in maintenance culture medium (Millipore), containing $20 \mathrm{ng} / \mathrm{ml} \mathrm{FGF-2} \mathrm{and} 20 \mathrm{ng} / \mathrm{ml}$ of rhEGF. The following day, the medium was changed to maintenance medium without growth factors to induce differentiation. Cells were allowed to differentiate for 3 days in the presence or absence of the employed ECVs. To block RAGE signaling, selected NPC cultures were pretreated with $500 \mathrm{nM}$ FPS for $2 \mathrm{~h}$, followed by coexposure with ECVs for 3 days. After 3 days, cells were washed with PBS, fixed with ethanol for $30 \mathrm{~min}$ at $4{ }^{\circ} \mathrm{C}$, and subjected to immunostaining for $\mathrm{Hu} C / \mathrm{D}, \mathrm{NeuN}$, and DCX markers to assess neurons at different stages of development. Fluorescence images were acquired randomly through a confocal laser-scanning microscope (Olympus Fluoview 1200) and analyzed using FV10-ASW3.1 software. $\mathrm{Hu} C / \mathrm{D}, \mathrm{NeuN}$ positive and NeuN/DCX double positive cells were counted and expressed as percentage of the total cell number.

\section{Luminex MagPix assay}

Cell culture media samples collected after 3 days of differentiation were analyzed for cytokine/chemokine panel (G-CSF, IL-4, CCL2, Fractalkine, PDGF-AA, PDGF-AB/ BB, VEGF-A, BDNF, NGF- $\beta$; Milliplex MAP Human Cytokine/Chemokine Magnetic Bead Panel, Millipore Corp., Billerica, MA) following the kit-specific protocols provided by Millipore. Analytes were quantified using a Magpix analytical test instrument, which utilizes xMAP technology (Luminex Corp., Austin, TX), and xPONENT 4.1 software (Luminex). xMAP technology uses fluorescent-coded magnetic microspheres coated with analyte-specific capture antibodies to simultaneously measure multiple analytes in a specimen. After microspheres have captured the analytes, a biotinylated detection antibody binds to that complex. Streptavidin $\mathrm{PE}$ then attaches as a reporter molecule. Inside the instrument, magnetic beads are held in a monolayer by a magnet, where two LEDs are used to excite the internal micro-sphere dye and the dye of the reporter molecule, respectively. A CCD camera captures these images, which are then analyzed by Milliplex Analyst software (Millipore).

Concentrations of cytokines $(\mathrm{pg} / \mathrm{ml})$ were determined on the basis of the fit of a standard curve for mean fluorescence intensity versus $\mathrm{pg} / \mathrm{ml}$. Two quality controls were run with each assay (control 1, low level; control 2, high level.) All cytokines were found to fall within the quality control ranges except for VEGF-A. Therefore VEGF-A levels were separately determined with ELISA.

\section{Statistical analysis}

Data were analyzed using GraphPad Prism 6.0 (Graphpad Software, San Diego, CA). ANOVA was used to compare responses among treatments. Treatment means were compared using All Pairwise Multiple Comparison Procedures and $p<0.05$ was considered significant.

\section{Results \\ RAGE regulates generation of ECVs by HBMEC and their $A \beta$ levels}

ECVs were demonstrated to be involved in HIV and $A \beta$ pathology [15-21,37], and in intercellular transfer of $A \beta$ [22]. In addition, the RAGE pathway may both interfere with ECV release, as it was shown in macrophages [27], and with $A \beta$ accumulation in brain endothelial cells [14]. Therefore, we evaluated the involvement of RAGE in brain endothelial ECV secretion and regulation of their $A \beta$ cargo load. HBMEC were exposed to $30 \mathrm{ng} / \mathrm{ml}$ HIV particles and/or $100 \mathrm{nM} \mathrm{A} \beta(1-40)$ for $48 \mathrm{~h}$. Selected HBMEC cultures were pretreated with $500 \mathrm{nM}$ FPS-ZM1 (FPS, a specific RAGE inhibitor) for $2 \mathrm{~h}$, followed by co-treatment with $30 \mathrm{ng} / \mathrm{ml} \mathrm{HIV}$ particles and/or $100 \mathrm{nM} \mathrm{A} \beta(1-40)$ for $48 \mathrm{~h}$. ECVs released by HBMEC to the culture media were isolated and characterized for their number, size, and $A \beta$ content in the subsequent series of experiments.

Nanoparticle tracking analysis (NTA) was employed to quantify the number of ECVs produced by HBMEC in response to HIV, $A \beta$, and/or FPS. Compared to the control, treatment with FPS resulted in a significantly higher total ECV number in the media of treated HBMEC (Fig. 1a). While the majority of the remaining experimental groups showed a tendency to increase ECV levels as compared to controls, the changes were not significant. We then analyzed the impact of HIV and/or $A \beta$ on ECV levels grouped according to their dimensions, ranging from $<100-600 \mathrm{~nm}$ (Fig. 1b). Exposure of HBMEC to HIV plus $A \beta$ significantly elevated levels of $100-200$ 


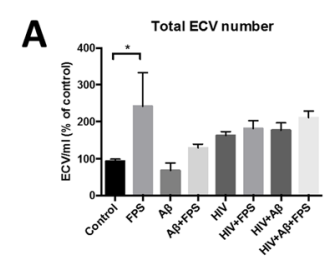

B
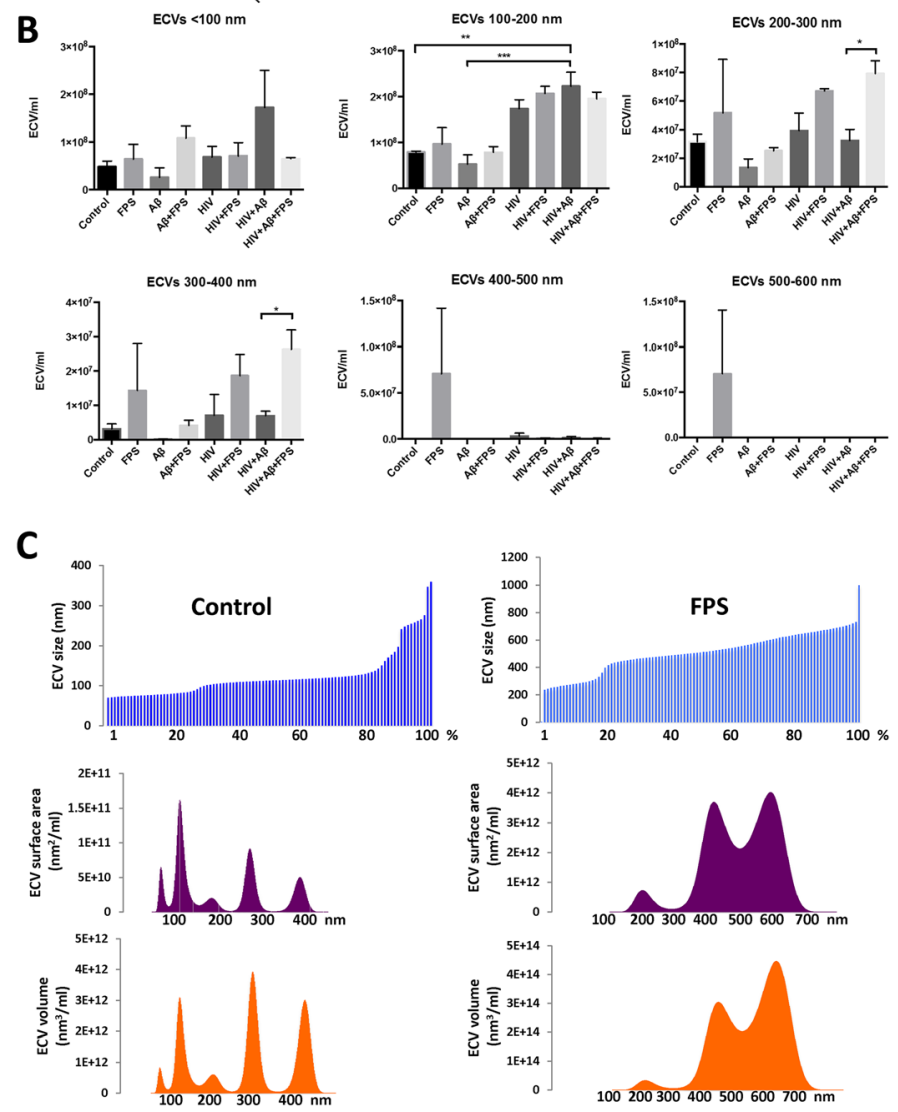

D
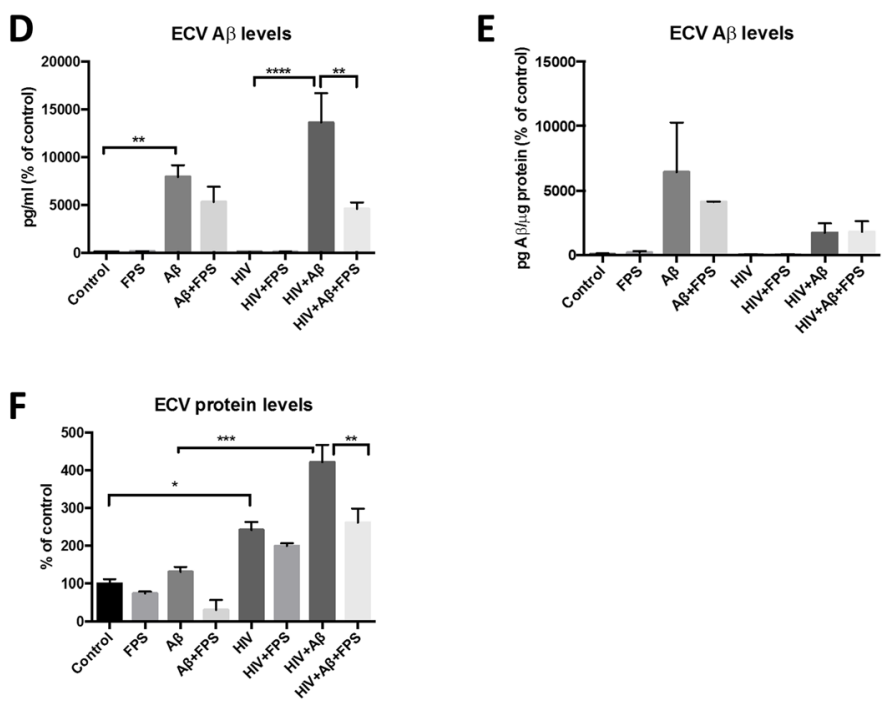

Fig. 1 (See legend on next page.) 
(See figure on previous page.)

Fig. 1 Release of brain endothelial ECVs and their A levels. HBMEC were exposed to $30 \mathrm{ng} / \mathrm{ml}$ HIV particles and/or 100 nM AB (1-40) for $48 \mathrm{~h}$. Selected cultures were pretreated with $500 \mathrm{nM}$ FPS-ZM1 (FPS) for $2 \mathrm{~h}$ followed by cotreatment with $30 \mathrm{ng} / \mathrm{ml} \mathrm{HIV} \mathrm{particles}$ and/or $100 \mathrm{nM} \mathrm{A \beta} \mathrm{(1-40)} \mathrm{for} 48 \mathrm{~h}$. ECVs were isolated from the culture media. a Total ECV number as measured by nanoparticle tracking analysis (NTA). Values are mean $\pm \mathrm{SEM} ; n=3-4$. $\mathbf{b}$ ECV number according to their size distribution and measured as in $\mathrm{A}$. Values are mean $\pm S E M ; n=3-4$. c Size, surface area, and volume distribution of ECVs shed by a representative control and FPS-treated HBMEC. $\mathbf{d}$ \& e ECV Aß (1-40) levels as measured by ELISA and normalized either to (d) media volume or (e) ECV protein levels. Values are mean $\pm S E M ; n=5-7$. $\mathbf{f} E C V$ protein levels as measured by the BCA assay. Values are mean $\pm S E M ; n=3-4$. Statistically significant at ${ }^{*} p<0.05,{ }^{* *} p<0.01$, or ${ }^{* *} p<0.001$

$\mathrm{nm}$ sized ECVs in the media as compared to the $\mathrm{A} \beta$ and the control groups. Similar tendency was observed for smaller (below $100 \mathrm{~nm}$ ) ECVs; however, the differences did not reach statistical significance. These groups of ECVs appear to be particularly important because their size corresponds to exosomes. Interestingly, a cotreatment with RAGE inhibitor increased the number of slightly larger ECVs, i.e., $200-300 \mathrm{~nm}$ and $300-400 \mathrm{~nm}$ ECVs in the HIV + A $\beta+$ FPS group as compared to the $\mathrm{HIV}+\mathrm{A} \beta$ group. Treatment with FPS alone had a tendency to increase levels of ECVs of larger sizes, such as $400-600 \mathrm{~nm}$ in dimension. While these effects were not statistically significant due to a high standard deviation, treatment with FPS alone profoundly affected the overall ECV size, surface area, and volume distribution as illustrated for the representative control and FPS samples (Fig. 1c).

We then analyzed the involvement of RAGE in the modulation of $A \beta$ cargo load in HBMEC-derived ECVs. Using the total population of ECVs from Fig. $1 \mathrm{a}, \mathrm{A} \beta(1-40)$ levels in ECV lysates were measured by ELISA (Fig. 1d and e). When normalized to the media volume, exposure of HBMEC to $100 \mathrm{nM} \mathrm{A} \beta$ (1-40) markedly increased $A \beta$ cargo load in ECVs. This effect was more pronounced by a co-exposure to HIV. Interestingly, $A \beta(1-40)$ levels were significantly downregulated in the HIV $+\mathrm{A} \beta-\mathrm{ECV}+\mathrm{FPS}$ as compared to the HIV + A $\beta$-ECVs (Fig. 1d). This FPSinduced effect changed when $\mathrm{A} \beta-\mathrm{ECV}$ levels were normalized not to the media volume but to ECV protein levels (Fig. 1e). Using this normalization approach, coexposure to FPS had a tendency to decrease $A \beta$ cargo in the $A \beta+$ FPS ECVs, but the changes were not statistically significant. At the same time, FPS had no impact on $A \beta$ levels in the $\mathrm{HIV}+\mathrm{A} \beta+$ FPS ECVs. The reason for the observed differences was a substantial impact of the employed treatment factors, including FPS, on the overall protein levels in ECVs. As shown in Fig. 1f, treatment with FPS significantly reduced protein levels in ECVs in the $\mathrm{HIV}+\mathrm{A} \beta+\mathrm{FPS}$ group as compared to the $\mathrm{HIV}+\mathrm{A} \beta$ group. In addition, a trend of decreasing protein load was noted in FPS-ECVs as compared to controls, and in the A $\beta+$ FPS-ECVs as compared to
A $\beta$-ECVs (Fig. 1f). At the same time, protein levels in the parent cells remained at the control levels and were not affected by the employed treatment factors (Additional file 1: Figure S2F). Overall, the results in Fig. 1 indicate that ECVs contain $A \beta$ as part of their cargo load. It also appears that RAGE has dual impact on this process, influencing both ECV number/ size and their $A \beta$ cargo. Indeed, treatment with FPS tends to decrease the total ECV protein cargo, while increasing ECV number and size.

In addition to RAGE, neutral sphingomyelinase (nSMase) was reported to be involved in ECV generation [38]. Therefore, we evaluated the impact of nSMase inhibition with GW4869 on production of ECVs by HBMEC and their $A \beta$ load. Blocking nSMase did not significantly affect ECVs production by HBMEC. When normalized to the media volume, GW4869 significantly decreased $A \beta$ levels in $A \beta$ - and $\mathrm{HIV}+\mathrm{A} \beta-\mathrm{ECV}$ s. However, these effects were not observed when the results were normalized to ECV protein levels (Additional file 1: Figure S2).

\section{RAGE affects the uptake of HIV + A $\beta-E C V$ s by neural progenitor cells (NPCs)}

ECVs shed by HBMEC can effectively transfer their cargo to the neighboring cells. Indeed, we demonstrated that HBMEC-derived ECVs can deliver $A \beta$ to astrocytes and pericytes [22], i.e., the cells of the neurovascular unit [39]. This process may also increase $A \beta$ exposure of other cells found in a close proximity to the brain microvessels, including NPCs located in neurogenic niches in the perivascular space [24]. Therefore, we next investigated whether the regulatory role of RAGE on the generation of ECVs by HBMEC and their $A \beta$ cargo can also impact $A \beta$ transfer to NPCs. In support of this line of investigation, RAGE was demonstrated to be expressed in adult hippocampal NPCs [25].

HBMEC were treated with $A \beta$ HiLyte and/or HIV, followed by isolation of ECVs as in Fig. 1. Then, human NPCs were exposed to these ECVs for $24 \mathrm{~h}$. Selected NPC cultures were also pretreated for $2 \mathrm{~h}$ with $500 \mathrm{nM}$ FPS, followed by cotreatment with ECVs for $24 \mathrm{~h}$. Transfer of $\mathrm{A} \beta$ from ECVs to recipient NPCs was assessed by measuring fluorescence intensity of $A \beta$ HiLyte (green) by 
confocal microscopy (Fig. 2a). NPC nuclei were stained with DRAQ5 (red). Quantification of the results revealed that the highest $A \beta$ uptake was observed in NPC cultures exposed to ECVs derived from HIV plus $A \beta$-treated HBMEC. This effect was statistically higher as compared to cultures treated alone with A $\beta$-ECVs and HIV-ECVs (Fig. 2b). Similar results were obtained when quantifying $A \beta$ uptake to the nuclei of the recipient NPCs (Fig. 2c). RAGE inhibition with FPS on the recipient NPCs significantly reduced nuclear transfer of $A \beta$ by $A \beta+$ HIV ECVs and exhibited a strong tendency to decrease the total cellular transfer of $A \beta$ by the same ECVs.

\section{ECV-mediated A $\beta$ transfer to NPCs is associated with} inflammasome protein changes

Both $A \beta$ pathology and HIV infection have been linked to the induction of the inflammasome pathway $[28,30]$.
Therefore, we explored the impact of HBMEC-derived $\mathrm{A} \beta$-ECVs and HIV $+\mathrm{A} \beta$-ECVs on the inflammasome pathway in the recipient NPCs. These experiments were performed without priming NPCs with LPS, as it is frequently done in the literature, so as not to mask the impact of the employed treatment factors. In addition, it was shown before that HIV Tat protein can prime and induce the NLRP3 inflammasome pathway [40]. HBMEC were treated, and ECVs were isolated as in Figs. 1 and 2, followed by exposure to NPCs for $24 \mathrm{~h}$. Similar to Fig. 2, selected NPC cultures were pretreated with $500 \mathrm{nM}$ FPS for $2 \mathrm{~h}$ to inhibit RAGE. The experiments focused on the NLRP3, a major pattern recognition receptor that is expressed in response to a variety of stimuli, including $\mathrm{A} \beta$ and HIV $[28,30]$, and on the adaptor protein called apoptosis-associated speck-like protein containing CARD (ASC), both critical mediators of the

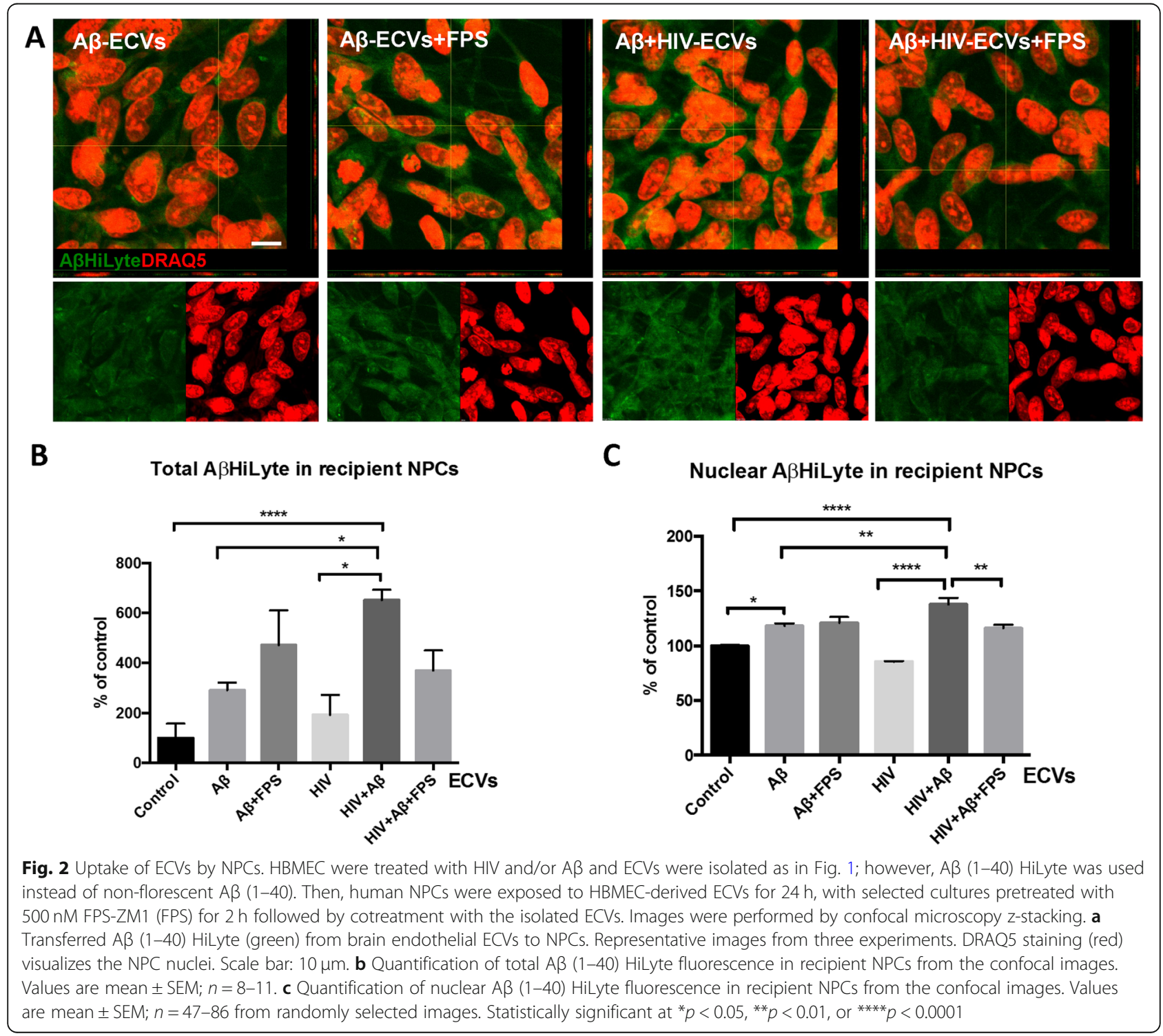


inflammasome pathway. We visualized the cellular distribution and the complex cellular/nuclear pattern of both NLRP3 and ASC by confocal microscopy.

Immunofluorescence microscopy for NLRP3 and ASC in NPCs after 24h ECV treatment revealed unexpected and unusual nuclear localization of both proteins (Fig. 3). NLRP3 immunoreactivity was mostly nuclear with a finer granular pattern (Fig. 3a). In addition, a small number of brighter cytoplasmic or extracellular immunoreactivity dots were apparent in all experimental groups (Fig. 3a, arrows). While the total NLRP3 expression was not affected by the employed treatment (Fig. $3 \mathrm{~b}$ and Additional file 1: Figure S3), NLRP3 levels significantly increased in the nuclei of NPCs as the result of A $\beta$-ECV and HIV $+A \beta$-ECV exposure (Fig. 3c). RAGE inhibition significantly decreased nuclear NLRP3 expression in NPCs exposed to A $\beta$-ECVs but modestly increased NLRP3 levels following HIV $+A \beta-$ ECV treatment (Fig. 3c).
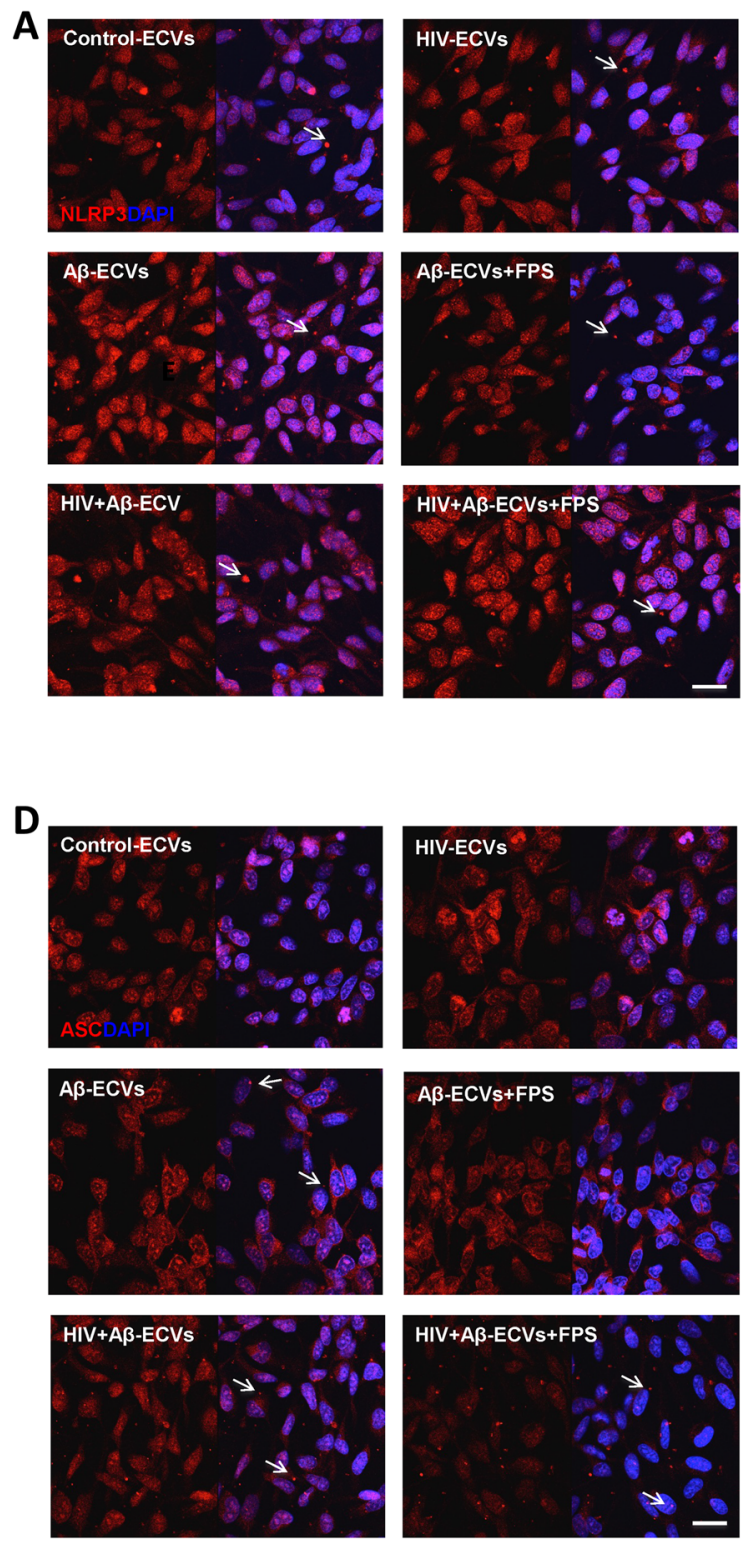

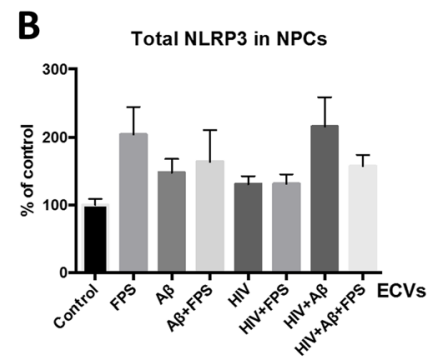

C Nuclear NLRP3 in NPCs
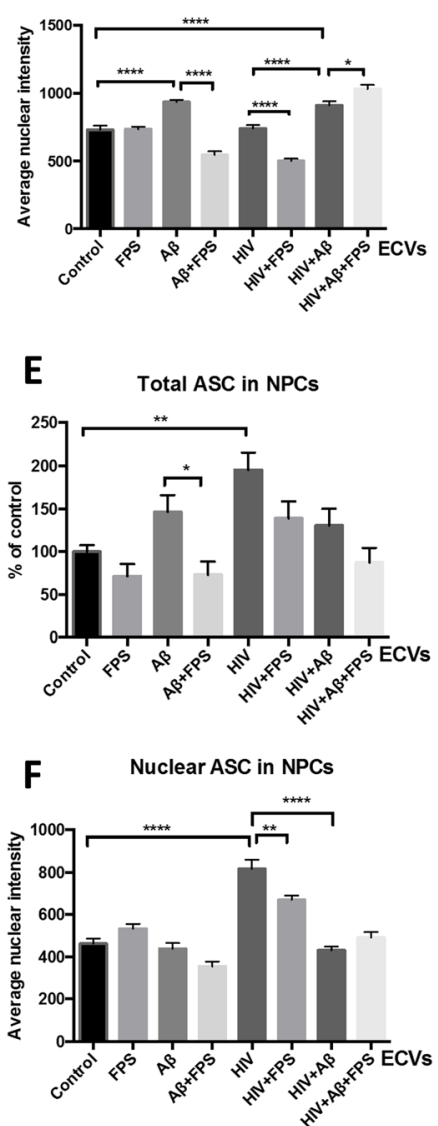

Fig. 3 ECV-mediated A $\beta$ transfer is associated with inflammasome protein changes in NPC. HBMEC were treated, and ECVs were isolated as in Fig. 2, followed by exposure to NPCs for $24 \mathrm{~h}$. a Representative images of NLRP3 immunoreactivity (red) in NPCs by confocal microscopy. Nuclei are stained with DAPI (blue). Scale bar: $20 \mu \mathrm{m}$. b Quantification of total and $\mathbf{c}$ nuclear NLRP3 from the confocal images. d Representative images of ASC immunoreactivity (red) in NPCs by confocal microscopy. Nuclei are stained with DAPI (blue). Scale bar: $20 \mu m$. e Quantification of total and f nuclear ASC from the confocal images. Values are mean \pm SEM, $n=3-7$ (total); $n=47-86$ (nuclear). Statistically significant at ${ }^{*} p<0.05,{ }^{* *} p<0.01$, ${ }^{* * *} p<0.001$, or ${ }^{* * *} p<0.0001$ 
Regarding ASC expression, its immunoreactivity was distributed overwhelmingly in the nuclear area with an intense granular pattern consisting of different sized nuclear granules in control cells. Following A $\beta-E C V$ exposure, this pattern remained primarily nuclear; however, several bright punctate immunoreactivity spots localized to the cytoplasm or the extracellular space appeared (Fig. 3d, arrows). In NPCs treated with HIV $+\mathrm{A} \beta-\mathrm{ECVs}$, alike ASC immunoreactive specks of different sizes were observed (arrows) in a similar location. Interestingly, the ASC specks were also visualized in the nuclei of cells exposed to HIV + A $\beta$-ECVs+FPS along with comparable immunoreactive patterns in the cytoplasm and/or extracellular space (arrows).

Total ASC immunoreactivity significantly increased in NPCs treated with HIV-ECVs. Interestingly, RAGE inhibition significantly decreased ASC levels after A $\beta$ ECVs exposure (Fig. 3e). Nuclear ASC expression largely mirrored the changes in the total levels of this protein, as HIV-ECVs induced the highest increase in ASC immunoreactivity compared to controls. RAGE inhibition decreased nuclear ASC in NPCs exposed to HIV-ECVs in the presence of FPS as compared to treatment with HIV-ECVs alone (Fig. 3f).

\section{RAGE modulates nuclear colocalization of $A \beta$ with inflammasome proteins}

Knowing that exposure to HIV and/or A $\beta$-ECVs can alter distribution of inflammasome proteins in the nuclei of NPCs, we next evaluated, using the single cell resolution of confocal microscopy, whether $\mathrm{A} \beta$ colocalizes with nuclear NLRP3 or ASC upon the employed treatment factors. NPCs were treated as in Figs. 2 and 3 with ECVs isolated from $A \beta$ and/or HIV-treated HBMEC as in Figs. 1, 2 and 3. Figure 4a depicts representative Zstack images of colocalization of NLRP3 (red fluorescence), A $\beta$ Hilyte (green fluorescence), and nuclei (DAPI, blue fluorescence). The majority of this colocalization occurs in the nuclei, and Fig. 4b illustrates the approach to quantify the nuclear A $\beta / N L R P 3$ colocalization index and Pearson's correlation coefficient, both shown on Fig. 4c. Exposure to A $\beta$-ECVs and HIV + A $\beta$-ECVs significantly increased NLRP3 colocalization with $A \beta$ (Fig. 4c). The effect of RAGE inhibition was different in the absence or presence of HIV. Specifically, FPS blocked the colocalization of A $\beta$ with NLRP3 when no HIV was present, i.e., in the A $\beta-E C V s+F P S$ group as compared to the $\mathrm{A} \beta-\mathrm{ECV}$ group, when analyzing the results by the colocalization index. In contrast, colocalization between $A \beta$ and NLRP3 was significantly increased in the cells exposed to HIV + A $\beta$-ECVs+FPS as compared to HIV + A $\beta$-ECVs (Fig. 4c).

Figure $4 \mathrm{~d}$, e depict patterns of $\mathrm{A} \beta$ nuclear colocalization with ASC in NPCs treated with ECVs and/or FPS as in Fig. 4a-c. The colocalization was significantly increased as the result of $\mathrm{A} \beta-\mathrm{ECV}$ exposure as compared to the background levels of control-ECVs (Fig. 4f). In addition, RAGE inhibition significantly blocked this effect. In the presence of ECVs isolated from HIV and A $\beta$ treated HBMEC, no such colocalization changes took place for ASC. The individual channels representing staining for NLRP3/ASC and A $\beta$ HiLyte fluorescence from Fig. 4a and d are shown as Additional file 1: Figure S4. Overall, the results from Fig. 4 indicate that blocking RAGE activity in NPCs can profoundly impact $A \beta$-ECV and/or HIV-ECV-induced alterations of both ASC and NLRP3 localization to the nuclei of the recipient cells. In addition, ASC changes are consistent with the notion that in order to engage in the inflammasome pathway, a transfer from the nuclei into the cytoplasm is required [41]. Indeed, no changes in the inflammasome pathway end-players, such as caspase 1 activity and/or IL-1 $\beta$ levels, were detected after the employed ECV exposure (Additional file 1: Figure S3C-E), suggesting that the classical inflammasome pathway was not induced in NPCs.

\section{RAGE inhibition selectively affects differentiation of NPCs to mature neurons}

In the next series of experiments, we evaluated the impact of the employed treatment factors on differentiation of NPCs to mature neurons. The rationale of these experiments was enhanced by a report that $A \beta$ can affect neuronal differentiation via the inflammasome pathway involving RAGE [25]. NPCs were differentiated for 3 days as previously described $[42,43]$ in the presence of ECVs and/or FPS as in Figs. 2, 3 and 4. Cell differentiation was evaluated by counting cells positive for the neuronal marker $\mathrm{Hu} C / \mathrm{D}$ [44], neuronal nuclear antigen (NeuN), a marker for mature neurons [45], and doublecortin (DCX), a marker of immature neurons [46]. In addition, the nuclei were stained with DAPI (blue). At least 9 images for every experimental condition from different samples were randomly acquired.

A prominent nuclear $\mathrm{Hu} \mathrm{C} / \mathrm{D}$ staining pattern was detected in the differentiated control cells; however, the number of $\mathrm{Hu} \mathrm{C} / \mathrm{D}$-positive cells was markedly diminished by exposure to ECVs derived from $A \beta$ treated HBMEC, suggesting impaired neuronal maturation (Fig. 5a, b). Interestingly, the number of $\mathrm{Hu} \mathrm{C} /$ $D$-positive cells was also significantly lower in the $\mathrm{HIV}+\mathrm{A} \beta-\mathrm{ECV}+\mathrm{FPS}$ group when compared to the $\mathrm{HIV}+\mathrm{A} \beta-\mathrm{ECV}$ s group, indicating that RAGE inhibition in the recipient NPCs diminished neuronal differentiation in response to A $\beta$-ECV transfer only in the presence of HIV (Fig. 5b). In addition, Additional file 1: Figure S5A-B reflect quantified total and nuclear intensity of $\mathrm{Hu} \mathrm{C} / \mathrm{D}$ immunoreactivity in 


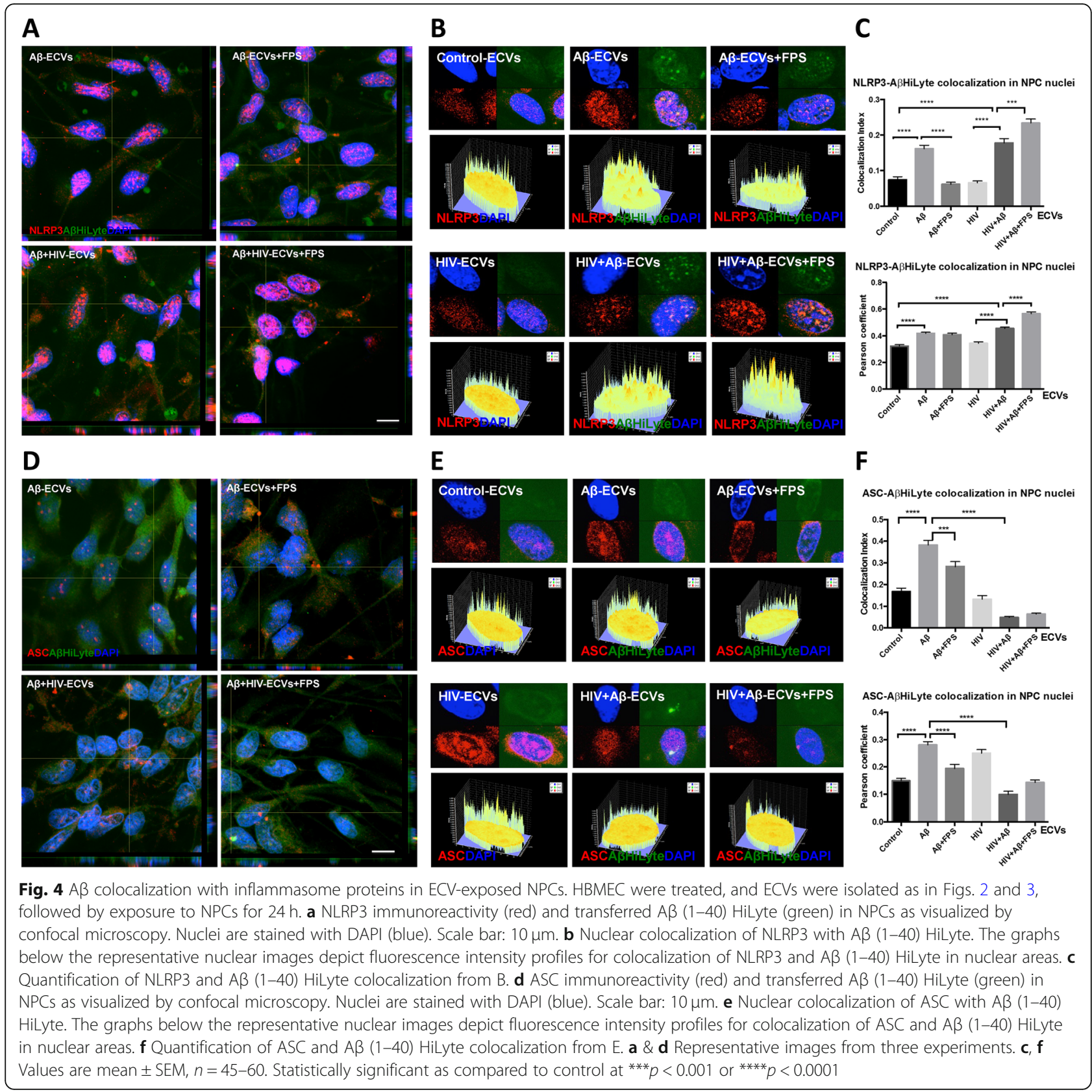

differentiated NPCs. Due to high standard deviation, there was no significant nuclear colocalization change between $\mathrm{Hu} C / \mathrm{D}$ and $A \beta$ in any of the studied groups (Additional file 1: Figure S5C).

Representative colocalization images of NeuN (green) and DCX (red) are presented on Fig. 5c. Quantification of the DCX-and/or NeuN-positive cells is illustrated in Fig. 5d-e, respectively. The number of NeuN positive cells was not affected by the A $\beta$-ECVs treatment; however, it was significantly increased in the presence of HIV-ECVs as compared to the control. RAGE inhibition significantly increased NeuN positive cell number in the
$\mathrm{A} \beta$-ECVs+FPS group as compared to the $\mathrm{A} \beta$-ECVs group (Fig. $5 \mathrm{~d}$ ). The number of NeuN/DCX double positive cells did not change significantly as the result of the employed treatment factors (Fig. 5e). Overall, these results suggest that $A \beta-E C V s$, HIV-ECVs, and/or RAGE inhibition have a modulatory effect on neuronal differentiation. The impact of RAGE inhibition on NPC differentiation fate is complex. On one hand, decreasing $\mathrm{Hu}$ $\mathrm{C} / \mathrm{D}$ immunopositive cell number after $\mathrm{A} \beta$-ECVs transfer in the presence of HIV; on the other hand, increasing the number of NeuN positive cells after $\mathrm{A} \beta$-ECV treatment without HIV. 

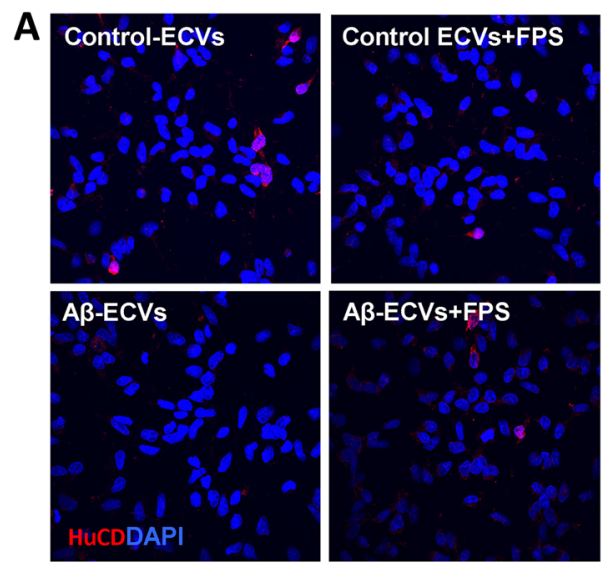

HuCD+cells

B
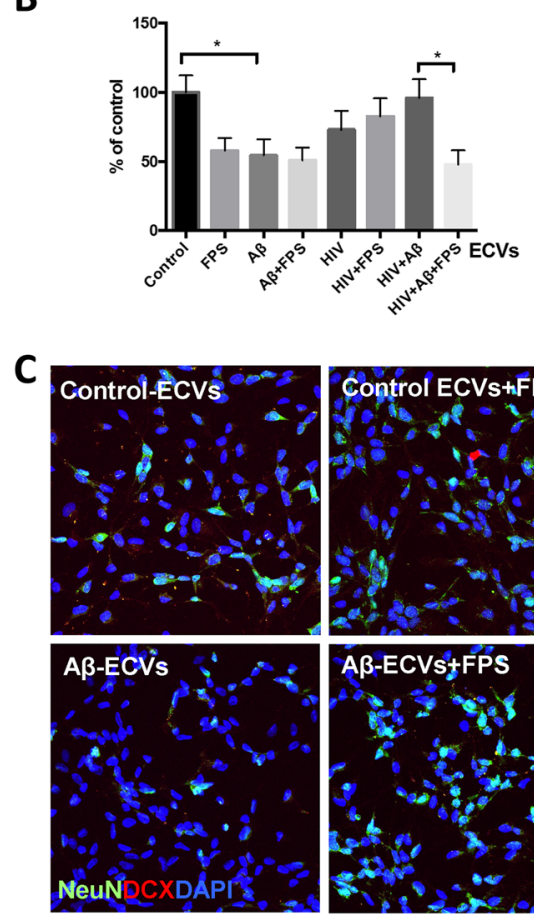

D

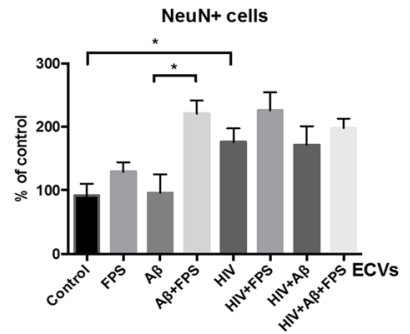

E
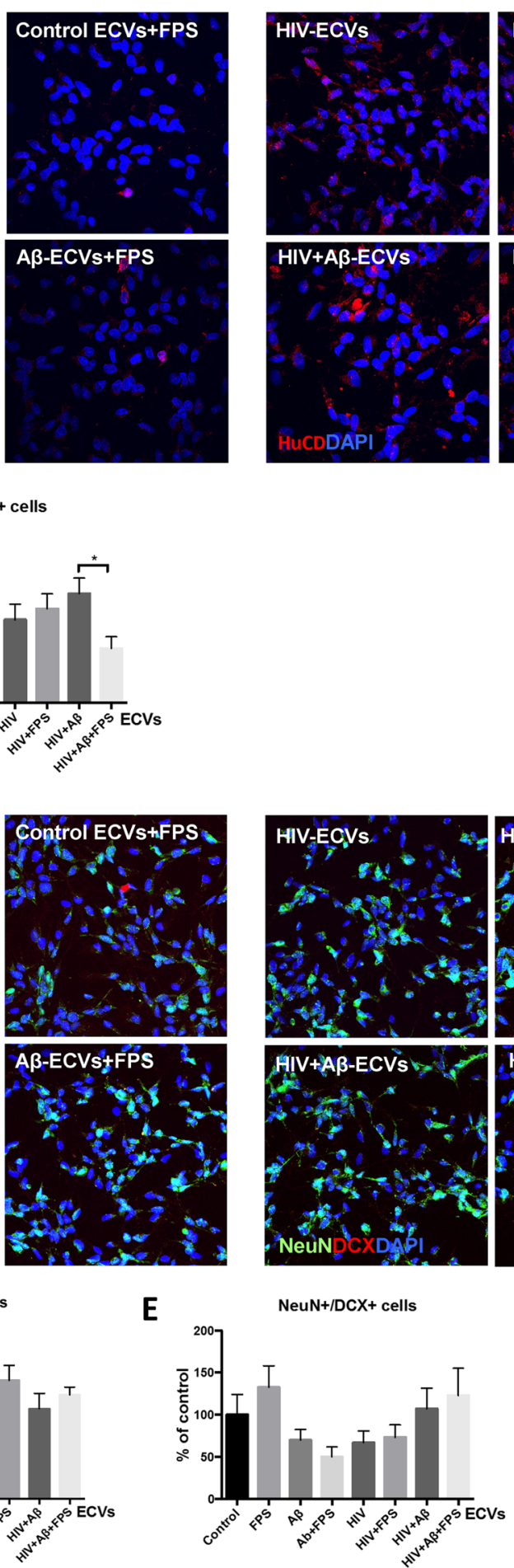
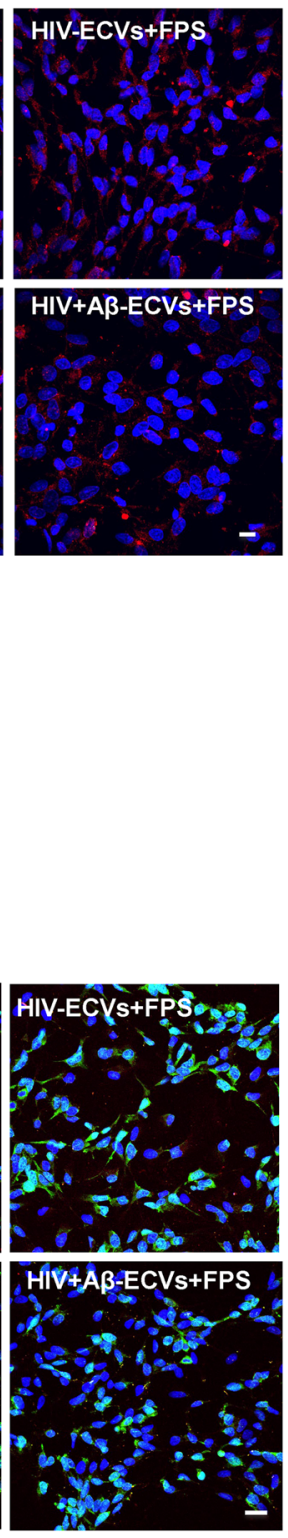

Fig. 5 (See legend on next page.) 
(See figure on previous page.)

Fig. 5 Impact of ECVs on NPC differentiation. HBMEC were treated with HIV and/or AB, and ECVs were isolated as in Fig. 1. NPC were differentiated for 3 days in the presence of HBMEC-derived ECVs. At the beginning of differentiation, selected NPC cultures were pretreated with $500 \mathrm{nM}$ FPS-ZM1 (FPS) for $2 \mathrm{~h}$ followed by cotreatment with the isolated ECVs. At the end of the 3-day differentiation, confocal microscopy was performed for neuronal markers. Neuronal differentiation was assessed by counting Hu C/D-, NeuN- and doublecortin (DCX) positive cells. At least 9 images for every experimental condition from different samples were randomly acquired. Scale bar: $20 \mu \mathrm{m}$. a Representative images of Hu C/D immunoreactivity (red); nuclei are stained with DAPI (blue). b Hu C/D positive cells were counted from confocal microscopy images. c

Representative images of NeuN (green) and doublecortin (DCX, red) immunoreactivity; nuclei are stained with DAPI (blue). $\mathbf{d}$ NeuN positive and e NeuN/DCX double positive cells were counted from confocal microscopy images. Values are mean \pm SEM, $n=30-43$ (Hu C/D); $n=7-15$ (NeuN); $n=13$ (NeuN/DCX). *Statistically significant as compared to control at $p<0.05$

\section{$A \beta$ - or HIV-ECVs-induced alterations of NPC}

differentiation are not associated with changes in soluble proinflammatory mediators

In the final series of experiments, we measured a panel of cytokines/chemokines/growth factors from the conditioned culture media of exposed NPCs after 3 days of differentiation. The panel included Fractalkine, G-CSF, IL-4, CCL-2, PDGF-AA, PDGF-AB/BB, and VEGF-A. We choose this panel based on a previous report suggesting its susceptibility to changes due to the presence or absence of bFGF, i.e., one of the growth factors that are being withdrawn from the culture medium to initiate differentiation [47]. Among the studied active compounds, the only significant change was an increase in VEGF-A levels in the media of differentiated NPCs exposed to HIV-ECVs+FPS as compared to HIV-ECVs (Fig. 6 and Additional file 1: Figure S6).

We also measured the brain-derived neurotrophic factor (BDNF) and the nerve growth factor- $\beta$ (NGF- $\beta$ ) because they provide signaling and trophic support during

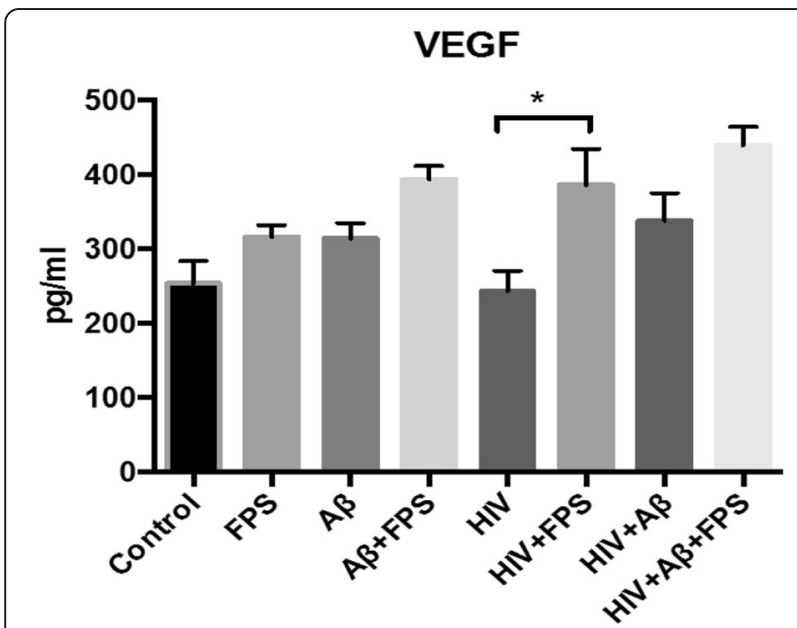

Fig. 6 Cytokine/chemokine panel after NPC differentiation. NPC were treated and differentiated as in Fig. 5. At the end of the 3-day differentiation, a cytokine/chemokine panel (G-CSF, IL-4, MCP-1, Fractalkine, PDGF-AA, PDGF-AB/BB, VEGF-A, BDNF, NGF- $\beta$ ) was measured by Luminex MagPix assay or ELISA from the cell culture media. Among the detected factors, only VEGF-A levels were significantly altered. Values are mean \pm SEM, $n=5-8$. *Statistically significant at $p<0.05$
NPC differentiation [48]. The levels of these growth factors were not detectable in NPC culture media 3 days after differentiation.

\section{Discussion}

ECVs are recognized as the carriers of biologically active proteins and genetic materials, such as mRNA, microRNA, siRNA, and DNA, which implicate them in the physiology and pathology of the CNS. However, the mechanisms of ECVs generation by the parent cells and the mechanisms of their uptake by the recipient cells are not fully understood. In this work, we examined two critical aspects of the involvement of RAGE in the ECVmediated $A \beta$ pathology in the context of HIV infection. First, we evaluated the role of RAGE in endothelial cellderived ECV release and A $\beta-E C V$ levels. Second, we examined the involvement of RAGE in the ECV-mediated transfer of $\mathrm{A} \beta$ to the neighboring neuronal progenitor cells (NPC) and its effects on neuronal differentiation.

Novel findings of the present study indicated that inhibition of RAGE in brain endothelial cells resulted in a significant increase in produced ECVs (Fig. 1a, b), and a decrease in $A \beta$ and protein levels in ECVs (Fig. 1d-f). These changes appeared to be specific because we did not observe any alterations in ECV number upon nSMase inhibition. Our results on the apparent lack of the role of nSMase in ECV production by HBMEC are in contrast to the literature reports that implicated this pathway in exosome generation [38] and in secretion of microvesicles from macrophages [27]. On the other hand, inhibition of nSMase decreased $\mathrm{A} \beta-\mathrm{ECV}$ levels, mimicking the input of RAGE inhibition, and suggesting that these pathways may be related in regulation of cellular $\mathrm{A} \beta$ release via ECVs.

ECVs derived from brain endothelial cells can transfer $A \beta$ to other cells of the neurovascular unit, such as astrocytes and pericytes [22]. Therefore, we hypothesized that ECVs may also deliver $A \beta$ to other neighboring cells, such as NPCs found in neurogenic niches in the perivascular space and close to the brain microvasculature [24]. Indeed, novel results reported in the current study indicate that ECVs can transfer $A \beta$ from the brain endothelial cells to NPCs, and that this process is facilitated in the context of $\mathrm{HIV}$ (Fig. 2). A $\beta$ was also 


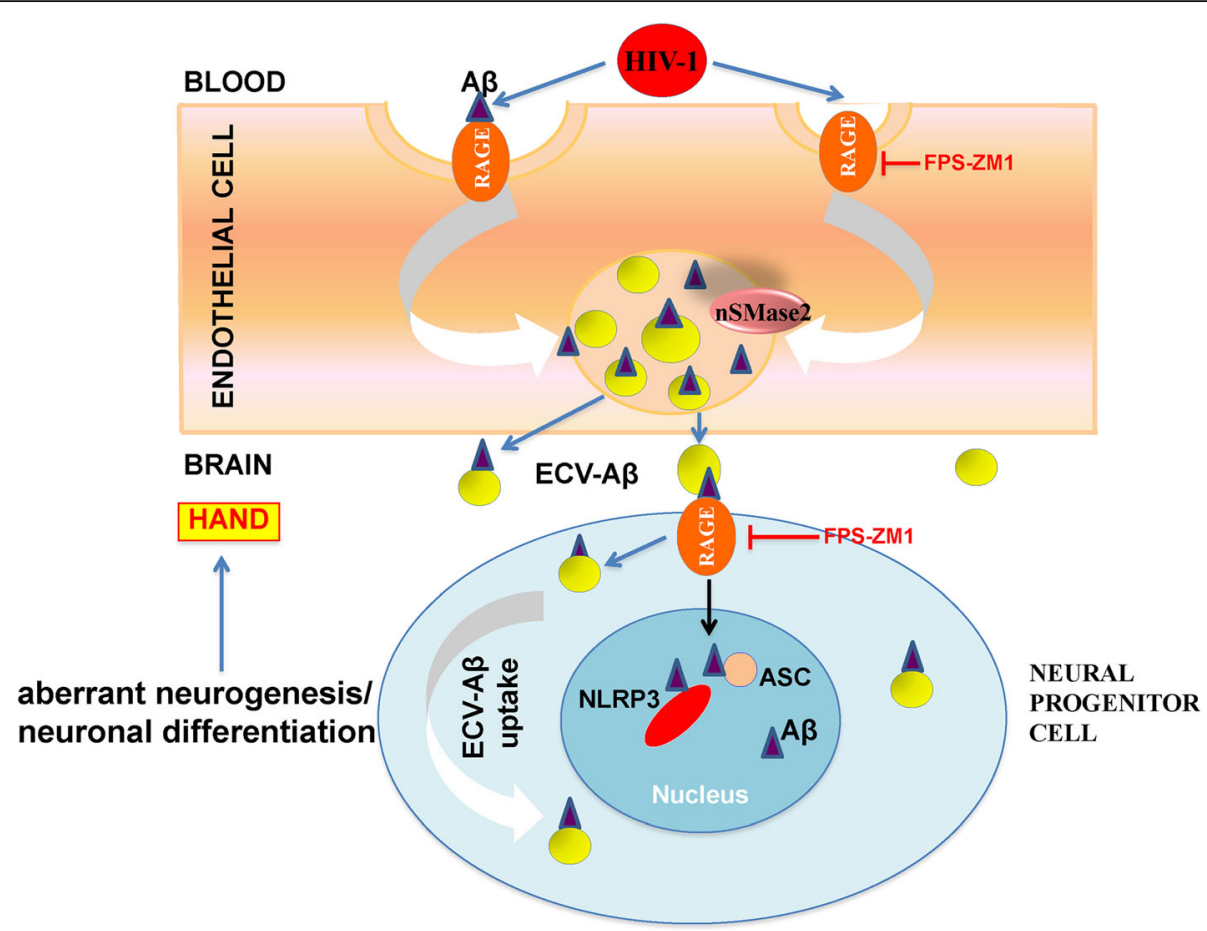

Fig. 7 Schematic diagram of the involvement of RAGE in brain endothelial ECV release and ECV-mediated Aß transfer to NPC. Our data indicate that RAGE affects HIV-induced brain endothelial ECV release and ECV-mediated A $\beta$ transfer to NPC. A $\beta$ uptake by NPC nuclei and colocalization with the inflammasome markers (NLRP3, ASC) are modulated by RAGE. These complex events affect NPC differentiation into neurons and may contribute to HIV associated neurocognitive disorders. Abbreviations: A 3 , amyloid beta; ECV, extracellular vesicle; HAND, HIV associated neurocognitive disorders; NPC, neural progenitor cell; RAGE, receptor for advanced glycation end products

delivered to the nuclei of the recipient NPCs, a process that can result in profound transcriptomic changes [49]. Furthermore, knowing that NPCs express RAGE [25], we evaluated the role of RAGE in A $\beta$ transfer to NPCs. While the total $A \beta$ transfer was not statistically affected by blocking RAGE, inhibition of this receptor significantly reduced $A \beta$ transfer to the nuclear compartment. Interestingly, a regulatory role of RAGE in $A \beta$ transfer was apparent only in the context of HIV (Fig. 2c), an observation that is consistent with the role of this transfer system in HIV infection [50].

In the next series of experiments, we investigated the implications of $A \beta$ transfer to NPCs by evaluating the inflammasome pathway and differentiation of NPCs to mature neurons. The inflammasomes are cytoplasmic complexes containing the danger signal sensing proteins of the NLR family, such as NLRP3 evaluated in the present study. The NLR proteins can then recruit the adaptor ASC (apoptosis-associated speck-like protein containing a caspase recruitment domain) and form cytoplasmic complexes, leading to activation of caspase1 as well as release of IL-1 $\beta$ and IL-18 [51].

Exposure to HIV-ECVs significantly increased the total and nuclear ASC levels. In addition, NLRP3 nuclear levels increased significantly after $\mathrm{HIV}+\mathrm{A} \beta$-ECVs exposure as compared to control. These results are consistent with the reported role of inflammasome in HIV infection [28, 52-54]. For example, NLRP3 and IL-1 $\beta$ polymorphisms were linked to an increased susceptibility to HIV infection $[55,56]$. ASC specs were found in the plasma of HIV positive patients [57], and infection with HIV stimulated the NLRP3 inflammasome in monocytes [58] as well as production of caspase-1, IL- $1 \beta$ and IL-18 in brain microglial cells [59]. HIV viral proteins, such as $\mathrm{Vpr}$ and Tat, were also demonstrated to activate the NLRP3 inflammasome in human microglia [40,60]. Finally, activation of the NLRP3 inflammasome in human monocytes has been shown in response to antiretroviral treatment [61].

Our novel observations also indicate that exposure to $A \beta-E C V s$ and $\mathrm{HIV}+\mathrm{A} \beta-\mathrm{ECVs}$ increased nuclear localization of NLRP3. This effect was associated with elevated $A \beta$ levels as the result of ECV-mediated $A \beta$ transfer to the recipient NPCs and was consistent with the role of the NLR proteins to recognize misfolded proteins, such as $A \beta$. Indeed, $A \beta$ was shown to activate the inflammasome pathway in LPS-primed macrophages [29]. In addition, when NLRP3-deficient mice were crossed with APP/PS1 transgenic mice, the offspring had no amyloid plaques and their 
neurobehavioral performance improved, suggesting a role of the NLRP3 inflammasome in the A $\beta$ pathology [62]. This notion was further supported by findings that inflammasome markers colocalized with $A \beta$ in human AD brains [30], and ASC was present in the core of amyloid plaques in both the mouse and human brains [63]. Moreover, ASC specs from microglia can cross-seed $A \beta$ and facilitate the formation of $A \beta$ oligomers and aggregates in vitro. Injection of ASC specs in the hippocampus of Alzheimer's disease mice initiates spreading of $A \beta$ pathology in the brain. This close connection between $A \beta$ and the inflammasome is further supported by the observations that $A \beta$ colocalized with both ASC and NLRP3 in the nuclei of NPCs, the effect that was modulated by RAGE inhibition.

While NPCs strongly expressed inflammasome proteins such as NLRP3 and ASC, the expression of these proteins was mostly localized to nuclei, with occasional brighter ASC specks in the cytosol or in the extracellular space in the A $\beta$-ECVs, HIV $+\mathrm{A} \beta$ ECVs and HIV + A $\beta$-ECVs+FPS groups. The nuclear localization of NLRP3 and ASC cannot fully explain their potential role in the inflammasome assembly, which takes place in the cytosol. In fact, it was proposed that inducible redistribution of ASC from the nucleus to the cytoplasm is necessary for the inflammasome response $[41,64]$. These observations are in line with the fact that no caspase- 1 activation was observed in NPCs after the employed treatment, and the levels of IL- $1 \beta$ were inconsistent; however, mostly negative under these conditions. RAGE inhibition modulated levels and cellular localization of both ASC and NLRP3 in response to $\mathrm{A} \beta$ and/or HIV-ECVs exposure, supporting the notion that RAGE can signal through the NLRP3 inflammasome [31].

Although both $A \beta$ and HIV pathology was linked to the NLRP3 inflammasome, i.e., the pathway that was examined in the present study, other types of inflammasomes may also be involved in the observed effects. For instance, AIM2 is the dominant inflammasome sensor in the mouse brain. Its deletion caused a decrease in $A \beta$ deposition and microglial activation along with IL-6 and IL-18 increase [65]. In the serum of HIV patients with higher viral load, AIM2 gene expression increased along with NLRP3, ASC, IL-1 $\beta$, and IL-18 [66]. In another report $A \beta$ oligomers were demonstrated to disturb the neuronal membrane causing $\mathrm{K}+$ efflux from the cell. The low intracellular $\mathrm{K}+$ concentration may activate the NALP1 inflammasome leading to IL- $1 \beta$ and IL-18 increase [67]. In fact, $A \beta$ was shown to induce NLRP1-dependent neuronal pyroptosis, as NLRP1 was upregulated in cultured cortical neurons leading to caspase-1 dependent pyroptosis [68]. Recently, HIV Tat was shown to downregulate NLRC5 in vitro via the miRNA-34a-NLRC5-NFKB signaling axis leading to an IL-1 $\beta$ level increase. NLRC5 was also downregulated in HIV transgenic rats and SIV infected macaques [69].

Another long-term outcome of $A \beta$ transfer to NPCs may be aberrant differentiation of these cells to mature neurons. The process is important as adult hippocampal neurogenesis was demonstrated to play a role in learning and memory $[70,71]$ and neurocognitive dysfunction was linked to aberrant NPC neurogenesis [72]. Novel findings of the current study indicate that both $A \beta-E C V s$ and RAGE inhibition altered NPC differentiation. Specifically, the number of $\mathrm{HuC} / \mathrm{D}$ positive cells was significantly decreased in NPCs exposed to A $\beta$-ECVs. Interestingly, RAGE inhibition also decreased $\mathrm{Hu} C /$ $\mathrm{D}+$ cell number in the $\mathrm{HIV}+\mathrm{A} \beta-\mathrm{ECV}+\mathrm{FPS}$ group as compared to the HIV + A $\beta$-ECVs group. On the other hand, RAGE inhibition increased the number of NeuN positive cells in the A $\beta$-ECVs+FPS group versus the $A \beta-E C V$ group. These results indicate the complex effects of $\mathrm{A} \beta-\mathrm{ECV}$ s on NPC differentiation with and without HIV; however, they are consistent with the observations that $A \beta$ profoundly affects NPC differentiation and the inflammasome via the $\mathrm{A} \beta$-(HMGB-1)-RAGE/NF-kB-NLRP3 pathway, further confirming the findings from the current study. The mechanisms of this effect are related to the fact that NF- $\mathrm{KB}$ can bind to the NLRP3 promoter followed by inflammasome activation, neuroinflammation, and neurotoxicity [25]. In our experiments, exposure to HIV-ECVs increased NeuN positive cell number. These results are in line with the literature reports demonstrating that NPCs could be infected with HIV [73-75] and HIV affected their proliferation and survival in vitro and in vivo [73, 76]. Moreover, the number of hippocampal NPCs in postmortem brains in HIV patients with dementia was lower when compared to patients without dementia [26].

In summary, results of the present study indicate that ECVs can efficiently transfer $A \beta$ from brain endothelial cells to the neighboring NPCs. Importantly, this process is influenced by HIV and regulated, at least in part, by RAGE (Fig. 7). The longterm effect of $A \beta$ transfer to NPCs includes alterations of NPC differentiation via a mechanism that may involve changes to the inflammasome machinery. Overall, these changes may contribute to the development of neurocognitive impairment and $A \beta$ pathology in HIV-infected brains. 


\section{Supplementary information}

Supplementary information accompanies this paper at https://doi.org/10. 1186/s13041-020-0562-0

Additional file 1: Figure S1. HBMEC-derived ECVs. Figure S2. The effects of nSMase inhibition on brain endothelial ECV release and ECV-AB levels. Figure S3. Analysis of NLRP3, ASC, caspase-1, and IL-1 $\beta$. Figure S4. Impact of HBMEC-derived ECVs on colocalization of NLRP3 and ASC with $A \beta$ in NPCs. Figure S5. Impact of ECV-mediated A 3 transfer on NPC differentiation as measured by HuC/D. Figure S6. Cytokine/chemokine panel after NPC differentiation.

\section{Abbreviations}

AD: Alzheimer's disease; ASC: Apoptosis-associated speck-like protein containing CARD; AB: Amyloid beta; BBB: Blood-brain barrier; BDNF: Brainderived neurotrophic factor; CCL2: C-C motif chemokine ligand 2; DAPI: 4',6diamidino-2-phenylindole; DCX: Doublecortin; ECVs: Extracellular vesicles; EGF: Epidermal growth factor; ELISA: Enzyme linked immunosorbent assay; FPS: FPS-ZM1; G-CSF: Granulocyte colony stimulating factor; HAND: HIVassociated neurocognitive disorders; HBMEC: Human brain microvascular endothelial cells; HIV: Human immunodeficiency virus type 1; HuCD: Human HuC/HuD neuronal protein; IL-18: Interleukin 18; IL-1ß: Interleukin 1 beta; IL4: Interleukin 4; LPS: Lipopolysaccharide; NeuN: Neuronal nuclear antigen; NGF- $\beta$ : Nerve growth factor beta; NLRP3: NLR family pyrin domain containing 3; NPCs: Neural progenitor cells; nSMase: Neutral sphingomyelinase; NTA: Nanoparticle tracking analysis; PBS: Phosphate buffered saline; PDGF-AA: Platelet derived growth factor-AA; PDGF-AB/ BB: Platelet derived growth factor-AB/BB; RAGE: Receptor for advanced glycation end products; VEGF-A: Vascular endothelial growth factor A

\section{Acknowledgements}

Not applicable.

\section{Authors' contributions}

AIE and MT participated in research design, wrote or contributed to the writing of the manuscript; AIE, MGC, CY, PP, BS and LD conducted experiments; AIE performed data analysis and created all figures. MT provided funding. All authors read and approved the final manuscript.

\section{Funding}

pYK-JRCSF was obtained from the AIDS Research and Reference Reagent Program, Division of AIDS, NIH/NIAID. Supported by the Florida Department of Health grant 8AZ24 and the National Institutes of Health (NIH), grants MH072567, MH098891, HL126559, DA039576, DA040537, DA044579, and DA047157. We also acknowledge support from the Miami Center for AIDS Research (CFAR) at the University of Miami Miller School of Medicine funded by a grant (P30Al073961) from the $\mathrm{NIH}$, which is supported by the following $\mathrm{NIH}$ Co-Funding and Participating Institutes and Centers: NIAID, NCI, NICHD, NHLBI, NIDA, NIMH, NIA, NIDDK, NIGMS, FIC AND OAR.

\section{Availability of data and materials}

The datasets analyzed during the current study available from the corresponding author upon request.

\section{Ethics approval and consent to participate}

Not applicable.

\section{Consent for publication}

Not applicable.

\section{Competing interests}

The authors declare that they have no competing interests.

\section{Author details}

${ }^{1}$ Department of Biochemistry and Molecular Biology, University of Miami School of Medicine, 1011 NW 15th Street, Gautier Building, Room 528, Miami, FL 33136-1019, USA. Diabetes Research Institute, University of Miami School of Medicine, 1450 NW 10th Ave, Miami, FL 33136-1011, USA.
Received: 14 November 2019 Accepted: 3 February 2020 Published online: 17 February 2020

\section{References}

1. Esiri MM, Biddolph SC, Morris CS. Prevalence of Alzheimer plaques in AIDS. J Neurol Neurosurg Psychiatry. 1998;65(1):29-33.

2. Rempel HC, Pulliam L. HIV-1 tat inhibits neprilysin and elevates amyloid beta. AIDS. 2005;19(2):127-35.

3. Xu J, Ikezu T. The comorbidity of HIV-associated neurocognitive disorders and Alzheimer's disease: a foreseeable medical challenge in post-HAART era. J Neurolmmune Pharmacol. 2009;4(2):200-12.

4. Brew BJ, Crowe SM, Landay A, Cysique LA, Guillemin G. Neurodegeneration and ageing in the HAART era. J Neurolmmune Pharmacol. 2009;4(2):163-74.

5. Achim CL, Adame A, Dumaop W, Everall IP, Masliah E, Neurobehavioral Research C. Increased accumulation of intraneuronal amyloid beta in HIVinfected patients. J Neurolmmune Pharmacol. 2009;4(2):190-9.

6. Pulliam L. HIV regulation of amyloid beta production. J Neurolmmune Pharmacol. 2009;4(2):213-7.

7. Soontornniyomkij V, Moore DJ, Gouaux B, Soontornniyomkij B, Tatro ET, Umlauf A, et al. Cerebral beta-amyloid deposition predicts HIV-associated neurocognitive disorders in APOE epsilon4 carriers. AIDS. 2012;26(18):2327-35.

8. Green DA, Masliah E, Vinters HV, Beizai P, Moore DJ, Achim CL. Brain deposition of beta-amyloid is a common pathologic feature in HIV positive patients. AIDS. 2005;19(4):407-11.

9. Steinbrink F, Evers S, Buerke B, Young P, Arendt G, Koutsilieri E, et al. Cognitive impairment in HIV infection is associated with MRI and CSF pattern of neurodegeneration. Eur J Neurol. 2013;20(3):420-8.

10. Bertrand L, Meroth F, Tournebize M, Leda AR, Sun E, Toborek M. Targeting the HIV-infected brain to improve ischemic stroke outcome. Nat Commun. 2019:10(1):2009.

11. Bertrand L, Cho HJ, Toborek M. Blood-brain barrier pericytes as a target for HIV-1 infection. Brain. 2019;142(3):502-11.

12. Deane R, Zlokovic BV. Role of the blood-brain barrier in the pathogenesis of Alzheimer's disease. Curr Alzheimer Res. 2007;4(2):191-7.

13. Deane R, Du Yan S, Submamaryan RK, LaRue B, Jovanovic S, Hogg E, et al. RAGE mediates amyloid-beta peptide transport across the blood-brain barrier and accumulation in brain. Nat Med. 2003:9(7):907-13.

14. Andras IE, Eum SY, Huang W, Zhong Y, Hennig B, Toborek M. HIV-1-induced amyloid beta accumulation in brain endothelial cells is attenuated by simvastatin. Mol Cell Neurosci. 2010;43(2):232-43.

15. Vella $L$, Sharples RA, Nisbet RM, Cappai R, Hill AF. The role of exosomes in the processing of proteins associated with neurodegenerative diseases. Eur Biophys J. 2008;37(3):323-32.

16. Kalani A, Tyagi A, Tyagi N. Exosomes: mediators of neurodegeneration, neuroprotection and therapeutics. Mol Neurobiol. 2014;49(1):590-600.

17. Gupta A, Pulliam L. Exosomes as mediators of neuroinflammation. J Neuroinflammation. 2014;11:68.

18. An K, Klyubin I, Kim Y, Jung JH, Mably AJ, O'Dowd ST, et al. Exosomes neutralize synaptic-plasticity-disrupting activity of Abeta assemblies in vivo. Mol Brain. 2013;6:47.

19. Yuyama K, Sun H, Sakai S, Mitsutake S, Okada M, Tahara H, et al. Decreased amyloid-beta pathologies by intracerebral loading of glycosphingolipidenriched exosomes in Alzheimer model mice. J Biol Chem. 2014;289(35): 24488-98.

20. Yuyama K, Sun H, Usuki S, Sakai S, Hanamatsu H, Mioka T, et al. A potential function for neuronal exosomes: sequestering intracerebral amyloid-beta peptide. FEBS Lett. 2015;589(1):84-8.

21. Dinkins MB, Dasgupta S, Wang G, Zhu G, He Q, Kong JN, et al. The 5XFAD mouse model of Alzheimer's disease exhibits an age-dependent increase in anti-Ceramide lgG and exogenous Administration of Ceramide Further Increases Anti-Ceramide Titers and Amyloid Plaque Burden. J Alzheimers Dis. 2015;46(1):55-61.

22. Andras IE, Leda A, Contreras MG, Bertrand L, Park M, Skowronska M, et al. Extracellular vesicles of the blood-brain barrier: role in the HIV-1 associated amyloid beta pathology. Mol Cell Neurosci. 2017;79:12-22.

23. Shen Q, Goderie SK, Jin L, Karanth N, Sun Y, Abramova N, et al. Endothelial cells stimulate self-renewal and expand neurogenesis of neural stem cells. Science. 2004;304(5675):1338-40.

24. Shen Q, Wang Y, Kokovay E, Lin G, Chuang SM, Goderie SK, et al. Adult SVZ stem cells lie in a vascular niche: a quantitative analysis of niche cell-cell interactions. Cell Stem Cell. 2008;3(3):289-300. 
25. Meneghini V, Bortolotto V, Francese MT, Dellarole A, Carraro L, Terzieva S, et al. High-mobility group box-1 protein and beta-amyloid oligomers promote neuronal differentiation of adult hippocampal neural progenitors via receptor for advanced glycation end products/nuclear factor-kappaB axis: relevance for Alzheimer's disease. J Neurosci. 2013;33(14):6047-59.

26. Krathwohl MD, Kaiser JL. HIV-1 promotes quiescence in human neural progenitor cells. J Infect Dis. 2004;190(2):216-26.

27. Chen Q, Bei JJ, Liu C, Feng SB, Zhao WB, Zhou Z, et al. HMGB1 induces secretion of matrix vesicles by macrophages to enhance ectopic mineralization. PLoS One. 2016:11(5):e0156686.

28. Doitsh G, Galloway NL, Geng X, Yang Z, Monroe KM, Zepeda O, et al. Cell death by pyroptosis drives CD4 T-cell depletion in HIV-1 infection. Nature. 2014:505(7484):509-14.

29. Halle A, Hornung V, Petzold GC, Stewart CR, Monks BG, Reinheckel T, et al. The NALP3 inflammasome is involved in the innate immune response to amyloid-beta. Nat Immunol. 2008;9(8):857-65.

30. Ahmed ME, lyer S, Thangavel R, Kempuraj D, Selvakumar GP, Raikwar SP, et al. Co-localization of glia maturation factor with NLRP3 Inflammasome and Autophagosome markers in human Alzheimer's disease brain. J Alzheimers Dis. 2017;60(3):1143-60.

31. Song Y, Wang Y, Zhang Y, Geng W, Liu W, Gao Y, et al. Advanced glycation end products regulate anabolic and catabolic activities via NLRP3inflammasome activation in human nucleus pulposus cells. J Cell Mol Med. 2017;21(7):1373-87.

32. Weksler BB, Subileau EA, Perriere N, Charneau P, Holloway K, Leveque M, et al. Blood-brain barrier-specific properties of a human adult brain endothelial cell line. FASEB J. 2005;19(13):1872-4.

33. Andras IE, Toborek M. HIV-1 stimulates nuclear entry of amyloid beta via dynamin dependent EEA1 and TGF-beta/Smad signaling. Exp Cell Res. 2014; 323(1):66-76.

34. Paris D, Townsend KP, Obregon DF, Humphrey J, Mullan M. Proinflammatory effect of freshly solubilized beta-amyloid peptides in the brain. Prostaglandins Other Lipid Mediat. 2002;70(1-2):1-12.

35. Deane R, Singh I, Sagare AP, Bell RD, Ross NT, LaRue B, et al. A multimodal RAGE-specific inhibitor reduces amyloid beta-mediated brain disorder in a mouse model of Alzheimer disease. J Clin Invest. 2012;122(4):1377-92.

36. Jozefowski S, Czerkies M, Lukasik A, Bielawska A, Bielawski J, Kwiatkowska K, et al. Ceramide and ceramide 1-phosphate are negative regulators of TNFalpha production induced by lipopolysaccharide. J Immunol. 2010;185(11): 6960-73.

37. Sampey GC, Meyering SS, Zadeh MA, Saifuddin M, Hakami RM, Kashanchi F. Exosomes and their role in CNS viral infections. J Neuro-Oncol. 2014;20(3): 199-208.

38. Yuyama K, Sun H, Mitsutake S, Igarashi Y. Sphingolipid-modulated exosome secretion promotes clearance of amyloid-beta by microglia. J Biol Chem. 2012;287(14):10977-89.

39. Abbott NJ, Friedman A. Overview and introduction: the blood-brain barrier in health and disease. Epilepsia. 2012;53(Suppl 6):1-6.

40. Chivero ET, Guo ML, Periyasamy P, Liao K, Callen SE, Buch S. HIV-1 tat primes and activates microglial NLRP3 Inflammasome-mediated Neuroinflammation. J Neurosci. 2017;37(13):3599-609.

41. Bryan NB, Dorfleutner A, Rojanasakul Y, Stehlik C. Activation of inflammasomes requires intracellular redistribution of the apoptotic specklike protein containing a caspase recruitment domain. J Immunol. 2009; 182(5):3173-82.

42. Frohlich M, Jaeger A, Weiss DG, Kriehuber R. Inhibition of BCL-2 leads to increased apoptosis and delayed neuronal differentiation in human ReNcell VM cells in vitro. Int J Dev Neurosci. 2016;48:9-17.

43. Jaeger A, Frohlich M, Klum S, Lantow M, Viergutz T, Weiss DG, et al. Characterization of apoptosis signaling cascades during the differentiation process of human neural ReNcell VM progenitor cells in vitro. Cell Mol Neurobiol. 2015;35(8):1203-16.

44. Hartig W, Reichenbach A, Voigt C, Boltze J, Bulavina L, Schuhmann MU, et al. Triple fluorescence labelling of neuronal, glial and vascular markers revealing pathological alterations in various animal models. J Chem Neuroanat. 2009;37(2):128-38

45. Mullen RJ, Buck CR, Smith AM. NeuN, a neuronal specific nuclear protein in vertebrates. Development. 1992;116(1):201-11.

46. Brown JP, Couillard-Despres S, Cooper-Kuhn CM, Winkler J, Aigner L, Kuhn HG. Transient expression of doublecortin during adult neurogenesis. J Comp Neurol. 2003;467(1):1-10.
47. Farrell K, Mahajan G, Srinivasan P, Lee MY, Kothapalli CR. Pediatric glioblastoma cells inhibit neurogenesis and promote astrogenesis, phenotypic transformation and migration of human neural progenitor cells within cocultures. Exp Cell Res. 2018;362(1):159-71.

48. Nierode GJ, Gopal S, Kwon P, Clark DS, Schaffer DV, Dordick JS. Highthroughput identification of factors promoting neuronal differentiation of human neural progenitor cells in microscale 3D cell culture. Biotechnol Bioeng. 2019;116(1):168-80.

49. Andras IE, Rampersaud E, Eum SY, Toborek M. Transcriptional profile of HIVinduced nuclear translocation of amyloid beta in brain endothelial cells. Arch Med Res. 2014;45(8):744-52.

50. Nasreddine N, Borde C, Gozlan J, Belec L, Marechal V, Hocini H. Advanced glycation end products inhibit both infection and transmission in trans of HIV-1 from monocyte-derived dendritic cells to autologous T cells. J Immunol. 2011;186(10):5687-95.

51. Martinon F, Mayor A, Tschopp J. The inflammasomes: guardians of the body. Annu Rev Immunol. 2009;27:229-65.

52. Chattergoon MA, Latanich R, Quinn J, Winter ME, Buckheit RW 3rd, Blankson $\mathrm{JN}$, et al. HIV and HCV activate the inflammasome in monocytes and macrophages via endosomal toll-like receptors without induction of type 1 interferon. PLoS Pathog. 2014;10(5):e1004082.

53. Guo H, Gao J, Taxman DJ, Ting JP, Su L. HIV-1 infection induces interleukin1 beta production via TLR8 protein-dependent and NLRP3 inflammasome mechanisms in human monocytes. J Biol Chem. 2014;289(31):21716-26.

54. Galloway NL, Doitsh G, Monroe KM, Yang Z, Munoz-Arias I, Levy DN, et al. Cell-to-cell transmission of HIV-1 is required to trigger Pyroptotic death of lymphoid-tissue-derived CD4 T cells. Cell Rep. 2015;12(10):1555-63.

55. Pontillo A, Brandao LA, Guimaraes RL, Segat L, Athanasakis E, Crovella S. A $3^{\prime}$ UTR SNP in NLRP3 gene is associated with susceptibility to HIV-1 infection. J Acquir Immune Defic Syndr. 2010;54(3):236-40.

56. Pontillo A, Oshiro TM, Girardelli M, Kamada AJ, Crovella S, Duarte AJ. Polymorphisms in inflammasome' genes and susceptibility to HIV-1 infection. J Acquir Immune Defic Syndr. 2012;59(2):121-5.

57. Ahmad F, Mishra N, Ahrenstorf G, Franklin BS, Latz E, Schmidt RE, et al. Evidence of inflammasome activation and formation of monocyte-derived ASC specks in HIV-1 positive patients. AIDS. 2018;32(3):299-307.

58. Pontillo A, Silva LT, Oshiro TM, Finazzo C, Crovella S, Duarte AJ. HIV-1 induces NALP3-inflammasome expression and interleukin-1beta secretion in dendritic cells from healthy individuals but not from HIV-positive patients. AIDS. 2012;26(1):11-8.

59. Walsh JG, Reinke SN, Mamik MK, McKenzie BA, Maingat F, Branton WG, et al. Rapid inflammasome activation in microglia contributes to brain disease in HIV/AIDS. Retrovirology. 2014;11:35.

60. Mamik MK, Hui E, Branton WG, McKenzie BA, Chisholm J, Cohen EA, et al. HIV-1 viral protein R activates NLRP3 Inflammasome in microglia: implications for HIV-1 associated Neuroinflammation. J Neurolmmune Pharmacol. 2017;12(2):233-48.

61. Toksoy A, Sennefelder H, Adam C, Hofmann S, Trautmann A, Goebeler M, et al. Potent NLRP3 Inflammasome activation by the HIV reverse transcriptase inhibitor Abacavir. J Biol Chem. 2017;292(7):2805-14.

62. Heneka MT, Kummer MP, Stutz A, Delekate A, Schwartz S, Vieira-Saecker A, et al. NLRP3 is activated in Alzheimer's disease and contributes to pathology in APP/PS1 mice. Nature. 2013;493(7434):674-8.

63. Venegas C, Kumar S, Franklin BS, Dierkes T, Brinkschulte R, Tejera D, et al. Microglia-derived ASC specks cross-seed amyloid-beta in Alzheimer's disease. Nature. 2017;552(7685):355-61.

64. Bryan NB, Dorfleutner A, Kramer SJ, Yun C, Rojanasakul Y, Stehlik C. Differential splicing of the apoptosis-associated speck like protein containing a caspase recruitment domain (ASC) regulates inflammasomes. J Inflamm (Lond). 2010;7:23.

65. Wu PJ, Hung YF, Liu HY, Hsueh YP. Deletion of the Inflammasome sensor Aim2 mitigates Abeta deposition and microglial activation but increases inflammatory cytokine expression in an Alzheimer disease mouse model. Neuroimmunomodulation. 2017:24(1):29-39.

66. Marin-Palma D, Castro GA, Cardona-Arias JA, Urcuqui-Inchima S, Hernandez JC. Lower high-density lipoproteins levels during human immunodeficiency virus type 1 infection are associated with increased inflammatory markers and disease progression. Front Immunol. 2018;9:1350.

67. Salminen A, Ojala J, Suuronen T, Kaarniranta K, Kauppinen A. Amyloid-beta oligomers set fire to inflammasomes and induce Alzheimer's pathology. J Cell Mol Med. 2008;12(6A):2255-62 
68. Tan MS, Tan L, Jiang T, Zhu XC, Wang HF, Jia CD, et al. Amyloid-beta induces NLRP1-dependent neuronal pyroptosis in models of Alzheimer's disease. Cell Death Dis. 2014;5:e1382.

69. Periyasamy P, Thangaraj A, Bendi VS, Buch S. HIV-1 tat-mediated microglial inflammation involves a novel miRNA-34a-NLRC5-NFkappaB signaling axis. Brain Behav Immun. 2019;80:227-37.

70. Aimone JB, Wiles J, Gage FH. Potential role for adult neurogenesis in the encoding of time in new memories. Nat Neurosci. 2006;9(6):723-7.

71. Lieberwirth C, Pan Y, Liu Y, Zhang Z, Wang Z. Hippocampal adult neurogenesis: its regulation and potential role in spatial learning and memory. Brain Res. 2016;1644:127-40.

72. Winner B, Winkler J. Adult neurogenesis in neurodegenerative diseases. Cold Spring Harb Perspect Biol. 2015;7(4):a021287.

73. Hahn YK, Podhaizer EM, Hauser KF, Knapp PE. HIV-1 alters neural and glial progenitor cell dynamics in the central nervous system: coordinated response to opiates during maturation. Glia. 2012;60(12):1871-87.

74. Lawrence DM, Durham LC, Schwartz L, Seth P, Maric D, Major EO. Human immunodeficiency virus type 1 infection of human brain-derived progenitor cells. J Virol. 2004;78(14):7319-28.

75. Skowronska M, McDonald M, Velichkovska M, Leda AR, Park M, Toborek M. Methamphetamine increases HIV infectivity in neural progenitor cells. J Biol Chem. 2018:293(1):296-311.

76. Lee MH, Wang T, Jang MH, Steiner J, Haughey N, Ming GL, et al. Rescue of adult hippocampal neurogenesis in a mouse model of HIV neurologic disease. Neurobiol Dis. 2011;41(3):678-87.

\section{Publisher's Note}

Springer Nature remains neutral with regard to jurisdictional claims in published maps and institutional affiliations.

Ready to submit your research? Choose BMC and benefit from:

- fast, convenient online submission

- thorough peer review by experienced researchers in your field

- rapid publication on acceptance

- support for research data, including large and complex data types

- gold Open Access which fosters wider collaboration and increased citations

- maximum visibility for your research: over $100 \mathrm{M}$ website views per year

At $\mathrm{BMC}$, research is always in progress.

Learn more biomedcentral.com/submissions 